http://dx.doi.org/10.18232/alhe.968

Artículos

\title{
Fiscalidad extraordinaria en una época de guerras atlánticas: los donativos y préstamos de la intendencia de Chiapas, $1780-1813$
}

\section{Added taxation in a time of Atlantic wars: the donations and loans of the Intendancy of Chiapas, 1780-1813}

\author{
José J. Guillén 1, * iD 0000-0002-3343-6623
}

${ }^{1}$ Benemérita Universidad Autónoma de Puebla, Puebla, México.

*Correspondencia: jjgvillafuerte@hotmail.com

Resumen. En las décadas recientes, la historiografía ha mostrado que la corona española demandó con frecuencia diversas contribuciones extraordinarias a sus vasallos de ambos lados del Atlántico para costear los gastos que generaron las guerras imperiales que peleó contra Inglaterra y Francia entre 1780 y 1813. En este artículo la atención se enfoca en un espacio periférico de la monarquía en América, la intendencia de Chiapas, y se estudia la relevancia que tuvo la recaudación de donativos y préstamos a interés para el financiamiento del déficit imperial en el ocaso de la época colonial.

Palabras clave: fiscalidad extraordinaria; reino de Guatemala; cajas de comunidad; capitales eclesiásticos.

Abstract. In the last decades, several studies have showed that Spanish monarchy required many added contributions from its vassals on both sides of the Atlantic to finance its defense expenses generated by their wars against France and England from 1780-1813. In this paper, our attention focus on a peripheral province of the monarchy in America, the intendancy of Chiapas, and We shall study the collection of donations and loans to cover the deficit of the imperial treasury during the last years of the colonial age.

CÓMO CITAR: Guillén, J. (2019). Fiscalidad extraordinaria en una época de guerras atlánticas: los donativos y préstamos de la intendencia de Chiapas, 1780-1813. América Latina en la Historia Económica, 26(3), e968.10.18232/alhe.968 
Key words: taxation; kingdom of Guatemala; cajas de comunidad; ecclesiastical capitals.

JEL: H390; N260.

Recibido: 3 de marzo de 2018.

Aceptado: 14 de agosto de 2018.

Publicado: 10 de mayo de 2019.

\section{INTRODUCCIÓN}

Especialmente este reino de Guatemala se distinguirá por su constante fidelidad, [y] también en las muestras de amor a su metrópoli, procurándole los socorros y auxilios que necesita más que nunca, los únicos que podemos darle desde esta distancia y los que tiene derecho a pedirnos y sin duda nos pedirá 11

En este artículo expongo los resultados de una investigación en curso en la cual estudio la participación de los habitantes del reino de Guatemala en general, y de la intendencia de Chiapas en particular, en el financiamiento de las guerras imperiales y la deuda pública del Estado borbónico durante el periodo tardocolonial. Como ha demostrado una abundante historiografía (Artola, 1982; Klein, 1994; Marichal, 1999; Torres, 2013), a partir de la década de 1780, la monarquía católica se vio envuelta en una serie de guerras contra Inglaterra y Francia, las cuales elevaron considerablemente sus gastos militares y los déficits del erario y la llevaron a contraer un volumen importante de deuda, factores que, finalmente, condujeron a la bancarrota del gobierno de Carlos IV (Artola, 1982, pp. 324-429; Marichal, 1995, pp. 243-249).

Para costear el esfuerzo bélico de la corona, los ministros del rey echaron a andar una serie de instrumentos de recaudación extraordinaria, entre los que destacaron el cobro de donativos, suplementos, préstamos con interés, contribuciones tomadas de las rentas de la Iglesia o descuentos forzosos a los sueldos de la burocracia. Así, durante el periodo que va de 1780 a 1814 , en el reino de Guatemala, al cual pertenecía la intendencia de Chiapas, se recaudaron seis donativos universales $(1781,1793,1798,1808$ y 1812), dos particulares (1809 y 1812) y tres empréstitos patrióticos con intereses $\left(1782,1798\right.$ y 1809) a los que se sumaron el subsidio eclesiástico ${ }^{2}$ el real valimiento de $4 \%$ deducido de los salarios de los ministros y oficiales reales (1794) ${ }^{3}$ y la aplicación de la Consolidación de Vales Reales (1805-1808).

\footnotetext{
${ }^{1}$ Fondo Diocesano, carp. 2737, exp. 1, Guatemala, 19 de septiembre de 1808. Archivo Histórico Diocesano de San Cristóbal de Las Casas (en adelante AHDSC).

${ }^{2}$ Acerca del origen y el cobro del subsidio eclesiástico en Nueva España, véase Aguirre (2014).

${ }^{3} \mathrm{El}$ real valimiento de $4 \%$ se pidió para hacer frente a los gastos de la guerra contra la Convención (1793-1796). Guatemala, A1, leg. 15, exp. 396. Archivo General de Centroamérica (en adelante AGCA).
} 
La mayor parte de la historiografía que analiza la recaudación de contribuciones fiscales extraordinarias en los territorios americanos de la monarquía enfoca su atención al virreinato de Nueva España ${ }^{4}$ y, en menor medida, contamos con trabajos que han esbozado el problema para los virreinatos andinos, concentrándose en la relación de los capitales de la Iglesia y su participación en el financiamiento de las guerras y la deuda pública de la corona (Quiroz, 1993).

En el caso del reino de Guatemala, el tema de la fiscalidad extraordinaria ha permanecido casi ausente del debate historiográfico sobre la segunda mitad del siglo XVIII y los años anteriores a la consumación de la independencia del istmo centroamericano en 1821. Pocos trabajos han hecho mención de manera tangencial sobre algunos de los donativos recaudados en estos años (Carvalho, 1994, p. 173; Fernández, 1993, pp. 178-180; González, 2015, pp. 189-190; Laughlin, 2001, pp. 169-170; Pollack, 2008, pp. 88-89; Wortman, 2012, pp. 266-267), y han ofrecido algunas estimaciones sobre los posibles efectos de la Consolidación de Vales Reales en la economía de la capitanía (Cabat, 1971; Fernández, 1993, p. 137; Wortman, 2012, pp. 223, 240-241). De esta manera, no se han estudiado a fondo las contribuciones extraordinarias de la población del reino, ni siquiera las del Consulado de Comerciantes de Guatemala, creado en 1793, las cuales, al parecer, alcanzaron montos considerables a partir de 17985

Con la finalidad de comenzar a llenar el silencio que ha guardado la historiografía sobre la Guatemala tardocolonial acerca de la política de financiamiento extraordinario que la corona puso en marcha a partir de 1780, en este artículo hemos concentrado nuestra atención en estudiar la recaudación de donativos y préstamos a interés en una de las provincias del reino para la cual se conservan abundantes registros en archivos civiles y eclesiásticos: la intendencia de Chiapas (véase mapa 1).

Antes de avanzar, consideramos que para resaltar la originalidad del caso de estudio resulta útil la comparación con el caso de Yucatán, intendencia para la cual la historiografía ha avanzado en la caracterización de una fiscalidad de una región periférica y sus métodos de financiamiento ordinario y extraordinario. Realicemos, pues, este ejercicio centrándonos en la respuesta de los erarios de ambas provincias ante los dos ciclos bélicos que enfrentó la monarquía entre 1780 y 1815 : el de las guerras interimperiales contra Inglaterra y Francia y el de la guerra interna ocasionada por el estallido de los movimientos insurgentes.

En principio, la Real Hacienda yucateca comparte una gran similitud con la de Chiapas: en ambas el tributo de indios fue la fuente de ingresos más importante durante el periodo que va

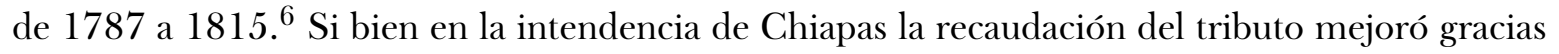
a una mayor eficacia en el empadronamiento de los tributarios, cuyo número creció a partir de la década de 1790 (Obara-Saeki y Viqueira, 2017, pp. 140-157), en Yucatán, además del factor demográfico, los ingresos de este ramo se elevaron como consecuencia de que la corona incautó las encomiendas de particulares (Cobá, 2009, pp. 68-69; Quezada y Moreno, 2005, p. 318), logrando así aumentar los ingresos del erario.

\footnotetext{
${ }^{4}$ En este sentido, la historiografía es amplia y muchos de los trabajos que la integran irán siendo citados a lo largo de este artículo. Por ahora anotamos los que consideramos de lectura obligatoria para inducirse al tema: Klein (1994), Marichal (1999), Sánchez (2016b) y Valle (2012, 2016).

${ }^{5}$ En 1798, el Consulado de Comerciantes de Guatemala donó 8925 pesos y prometió entregar más fondos en los meses siguientes. Estado, leg. 50, exp. 41, Guatemala, 3 de diciembre de 1798, f. 1. Archivo General de Indias (en adelante AGI).

${ }^{6}$ Ponemos como punto de partida 1787 porque fue en ese año cuando, tras la creación de la intendencia, se instaló nuevamente una Caja Real en Chiapas.
} 
MAPA 1. LA INTENDENCIA DE CHIAPAS (1787-1821)

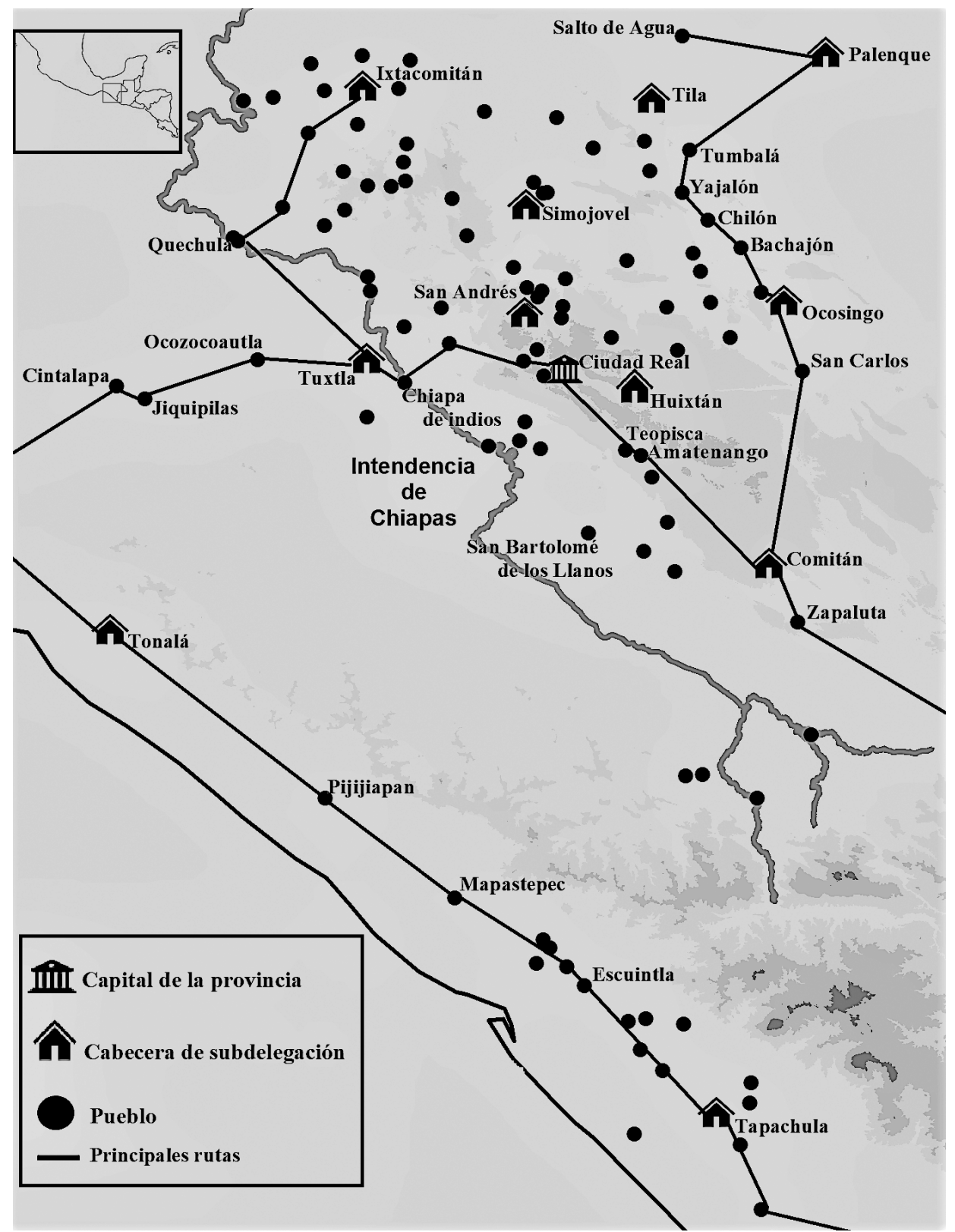

Fuente: elaborado con base en Obara-Saeki y Viqueira (2017, p. 143).

Por otro lado, si bien en las dos intendencias los ingresos fiscales derivados de los impuestos al comercio aumentaron en un inicio, en ambas estos disminuyeron o se estancaron en las décadas siguientes. En Yucatán estos comenzaron a decrecer a partir del decenio de 1790 (Quezada y Moreno, 2005, p. 322) y en Chiapas los ingresos de este rubro, que se integraba únicamente por el ramo de alcabalas, se estancaron durante el decenio siguiente en un promedio de 10000 pesos anuales (véase cuadro 1). No queda del todo claro si la baja recaudación alcabalatoria de la tesorería 


\section{CUADRO 1. INGRESOS DE LOS RAMOS DE TRIBUTOS Y ALCABALAS DE LA TESORERÍA DE CHIAPAS, 1791-1819 (EN PESOS)}

\begin{tabular}{lrr}
\hline & $\begin{array}{c}\text { Ingresos del ramo } \\
\text { de tributos de la tesorería } \\
\text { de Chiapas, 1791-1819 }\end{array}$ & $\begin{array}{c}\text { Ingresos del ramo } \\
\text { de alcabalas de la tesorería } \\
\text { de Chiapas, } 1791-1819\end{array}$ \\
\hline 1791 & 24925 & 8609 \\
1792 & 26252 & 11173 \\
1793 & 30456 & 10169 \\
1795 & 31776 & s. d. \\
1796 & 32606 & 8402 \\
1797 & 32463 & 5623 \\
1798 & 31985 & 13418 \\
1799 & 34956 & 10192 \\
1800 & 32890 & 13013 \\
1801 & 32189 & s. d. \\
1805 & 22984 & s. d. \\
1809 & 28462 & 8127 \\
1810 & 34760 & 9574 \\
1815 & 3304 & 5392 \\
1816 & 7030 & 10075 \\
1817 & 20554 & 7305 \\
1818 & 12190 & 6980 \\
1819 & 59510 & 7598 \\
\hline
\end{tabular}

Nota: cifras obtenidas en el marco del proyecto de investigación La Caja Real de Chiapas, 1787-1821, que llevo a cabo junto con Ana María Parrilla.

Fuente: Guatemala, 800. AGI. Chiapas, A3, leg. 14; Guatemala, A3, leg. 696, exp. 13032; leg. 2156, exp. 32312; leg. 283, exp. 6031; leg. 2350, exp. 34581; leg. 700, exp. 13059; Guatemala, B1.13, leg. 16, exp. 477. Todos en AGCA.

de Ciudad Real se debió a la poca cuantía de los intercambios comerciales de la provincia o si ello obedeció a que gran parte del comercio chipaneco se realizaba a través del contrabando, por lo cual sólo un porcentaje reducido de las mercancías que circulaban por la provincia se gravaba! 7

La gran diferencia entre ambos erarios se da en el terreno del déficit y el superávit. En Yucatán, los gastos militares asignados a las cajas de Mérida y Campeche -sobre todo el pago de los sueldos de la tropa y algunos gastos de defensa extraordinarios en época de guerra- superaron los ingresos de estas tesorerías de tal forma que el déficit estructural que se generó tuvo que ser cubierto a través de un situado enviado por la caja de México (Sánchez, 2012, pp. 338-340). Por

\footnotetext{
${ }^{7}$ De hecho, una de las razones para dividir la intendencia de Chiapas en un mayor número de partidos fue que los nuevos subdelegados establecieran una mayor vigilancia sobre el comercio y frenaran el contrabando. Así, uno de los argumentos que sirvieron para crear la subdelegación de Palenque fue que "[ese pueblo] es un paso interesante por las introducciones que se hacen de Campeche y otros parajes por el [...] río [de Catazajá] a esta intendencia”. Chiapas, A1, leg. 2, exp. 32, Ciudad Real, 30 de julio de 1803, f. 2 . AGCA.
} 
el contrario, la caja real de Chiapas mantuvo entre 1787 y 1819 un superávit anual que en promedio llegó a 12000 pesos, mismos que se enviaban como remesas a la caja matriz de Guatemala (Wortman, 2012, p. 360).

Tanto el erario de la intendencia de Yucatán como el de Chiapas resintieron los efectos de la presión fiscal ejercida por la corona, sobre todo, a partir del ciclo bélico que se inauguró tras el estallido de la guerra contra la Convención francesa (1793-1796). De esta forma, ante la necesidad de obtener recursos para financiar el gasto militar, la Real Hacienda yucateca incautó los sobrantes de las cajas de comunidad (Quezada y Moreno, 2005, p. 322; Tanck, 1994) y comenzó a recaudar un mayor número de donativos que se cobraron al conjunto de los sectores que conformaban la sociedad de la provincia, especialmente a los indios 8

En Chiapas la política de financiamiento extraordinario de la monarquía tuvo resultados similares. Así, la colecta de donativos aumentó a partir de la década de 1790 y, además, el superávit de los erarios de los pueblos de indios - el llamado fondo de comunidades-comenzó a invertirse en forma de empréstitos a interés destinados a la cobertura del déficit del erario tras la bancarrota del gobierno de Carlos IV.

Ni en Yucatán y ni en Chiapas aparecieron movimientos insurgentes como los que afectaron otras partes de Nueva España a partir de 1810.9 Sin embargo, los erarios de ambas provincias resintieron los efectos de la guerra y, además, se vieron afectados por algunas de las reformas fiscales decretadas por las cortes de Cádiz.

En este sentido, la abolición del tributo aplicada en Yucatán en 1810 y en Chiapas en 1812, privó a las tesorerías de ambas intendencias de 48 y $52 \%$ de sus ingresos, respectivamente ${ }^{10}$ Sin embargo, la situación del erario de la primera provincia se agravó más debido a que la guerra civil que afectó al reino orilló a las autoridades de la ciudad de México a cancelar el situado que recibía de manera regular desde el último tercio del siglo xviII (Cobá, 2009, pp. 122-134; Sánchez, 2012). A partir de ese momento, las cajas reales de la intendencia de Yucatán -Mérida y Campecheentraron en un periodo de insolvencia del cual comenzaron a salir gracias a la promulgación del Reglamento de Derechos del Comercio Libre y la reimplantación del tributo a finales de 1814 (Quezada y Moreno, 2005, pp. 328-330; Sánchez, 2012, pp. 344-345).

Si bien la caja de Ciudad Real no recibía un socorro de esta naturaleza, la tesorería de la ciudad de Guatemala sí dependía del situado anual de 100000 pesos enviado por la caja de México que también se suspendió tras el estallamiento de la insurgencia. En consecuencia, la población de Chiapas tuvo que financiar el déficit generado en la caja matriz del reino mediante el pago de la llamada suscripción patriótica, una especie de capitación universal decretada en abril de 1812 .

\footnotetext{
${ }^{8}$ Aunque en este artículo únicamente abordaremos los donativos y préstamos, es importante destacar que la fiscalidad extraordinaria también se tradujo en el pago de otras contribuciones. En el caso de Chiapas, por ejemplo, la Iglesia pagó un subsidio en la década de 1790 y los oficiales y ministros reales un "real valimiento" que consistió en descontar 4 \% de sus salarios para financiar la guerra. En Yucatán, por poner otro ejemplo, la Real Hacienda incautó a modo de préstamo los fondos de algunos ramos ajenos como el monte pío de cirujanos y el de bienes de difuntos (Sánchez, 2012 , p. 342). Lo anterior muestra que al igual que ocurría con la fiscalidad ordinaria (impuestos, monopolios, derechos y multas) con la extraordinaria existía una notable casuística que daba como resultado que en cada distrito fiscal se cobraran contribuciones de emergencia que posiblemente no eran recaudadas en otros.

${ }^{9}$ En el reino de Guatemala solamente se registraron algunos levantamientos en las capitales de las intendencias de León y San Salvador, sin embargo, estos no lograron articularse en un movimiento general que luchara por la independencia o autonomía del reino.

${ }^{10}$ El cálculo para Chiapas se hizo a partir de los libros comunes de 1798, 1799 y 1800 . Guatemala, 800. AGI.
} 
Una diferencia considerable que se generó en estos años entre ambos erarios se da en el terreno del gasto militar. El hecho de que Yucatán se mantuviera tan alejado de la guerra interna permitió a las autoridades provinciales reducir sus erogaciones de defensa, lo cual dio un respiro al erario de esa región. El caso de Chiapas fue diferente. Tras el arribo en 1812 del ejército de José María Morelos a Oaxaca, las autoridades de Guatemala, previendo una posible invasión de los rebeldes novohispanos a territorio centroamericano, trasladaron a Chiapas varias unidades militares que estaban acantonadas en la intendencia de Comayagua y Quetzaltenango (Wortman, 2012, p. 261). En términos financieros este escenario representaba un serio reto para la tesorería de Ciudad Real, pues sus gastos militares - la manutención y aprovisionamiento de las tropas que la protegíancrecían en un momento en el cual su principal ramo de ingresos, el tributo, había desaparecido. Así pues, la estrategia para financiar el déficit consistió en la recolección de varios préstamos a intereses exigidos a la Iglesia y a los pueblos de indios a través del dinero de sus cajas de comunidad.

La disipación de la amenaza insurgente a partir de 1815, el regreso de Fernando VII al trono español y la consecuente reinstauración del tributo, ahora con el nombre de contribución, permitieron a la tesorería de Chiapas superar el déficit. Así, a medida que los subdelegados elaboraban una nueva cuenta de tributarios y conseguían que estos pagaran (Obara-Saeki y Viqueira, 2017, p. 152), los ingresos del erario comenzaron a repuntar. De este modo, a diferencia de Yucatán en donde las arcas regionales salieron beneficiadas por el aumento en los ingresos mercantiles derivados de la aplicación del reglamento de derechos (Sánchez, 2012, p. 344), en Chiapas la crisis de 1812-1815 no produjo ninguna alteración a la estructura de ingresos del erario, la cual siguió dependiendo de la capitación indígena. Con todo, la relativa estabilidad que vivía la monarquía durante estos últimos años del dominio colonial y la recuperada salud de la tesorería provincial pusieron fin a la colecta de donativos y préstamos.

Para abordar la dinámica del financiamiento del déficit imperial desde Chiapas hemos divido este artículo en dos partes. Retomando el enfoque propuesto por Carlos Marichal (1999, pp. 9899), abordaremos en este trabajo los instrumentos de tipo antiguo y moderno a los que recurrió la monarquía para conseguir recursos adicionales ${ }^{11}$ En este sentido, en nuestro primer apartado analizaremos las diversas modalidades que tuvieron los donativos levantados (universales, particulares, voluntarios y forzosos) y los alcances de su recaudación en la provincia.

Posteriormente, abordaremos los diversos préstamos a interés que se recaudaron, principalmente, durante los gobiernos de Carlos IV y los años de la crisis dinástica de la monarquía. En este sentido buscaremos establecer la composición y los montos de la deuda pública que la corona contrajo en la provincia y, finalmente, abordaremos el tema del servicio de la deuda.

\footnotetext{
${ }^{11}$ Para Marichal (1999, pp. 26-27) la convivencia de instrumentos arcaicos y modernos se da a partir de la aplicación selectiva de dos principios de la política fiscal de la monarquía: la coacción y la negociación. En nuestro caso de estudio, la coacción se observa en los donativos forzosos recaudados en 1780 y 1809 y en los préstamos que, sin haberse negociado con los indios, se hicieron con dinero de las cajas de comunidad en 1801, 1805, 1806, 1807, 1809 y 1813. Por el contrario, el cobro de la suscripción de 1812, así como de los préstamos solicitados a la Iglesia en 1809 y 1813 estuvo marcada por una intensa negociación entre los agentes exactores de la Real Hacienda y el orden corporativo, en este caso, los cabildos indios y las corporaciones religiosas.
} 


\section{LOS DONATIVOS}

$\mathrm{Al}$ interior de la monarquía católica el donativo era una gracia que, libre y voluntariamente, los vasallos hacían al rey como muestra de "honor, lealtad y patriotismo" ${ }^{12}$ Fue común, pues, que ante "la urgente necesidad" de "atender a la defensa, decoro y prosperidad de la Monarquía", 13 la corona recurriera a este instrumento fiscal para allegarse dinero adicional en épocas de guerra.

Desde mediados del siglo XVI, el rey de España ordenó el levantamiento de diversos donativos en sus territorios de la Indias Occidentales ${ }^{14}$ En el reino de Guatemala, la primera petición de este tipo que hemos encontrado data de 1636 y fue solicitada para financiar las campañas militares en Flandes e Italia que la monarquía llevaba a cabo en el marco de la guerra de los Treinta Años. ${ }^{15}$ En 1650 , la corona volvió a requerir un donativo a sus vasallos de Guatemala 16 y en 1664 se recaudó otro donativo entre los habitantes del reino 17

El fin del gobierno de los Habsburgo y la llegada al trono español de los Borbones no acabó con la práctica de solicitar donativos para solventar los gastos bélicos de la corona. De hecho, durante la guerra de sucesión Felipe V, primer rey Borbón, ordenó recaudar nuevos donativos en sus reinos de las Indias (Escamilla, 2011, pp. 77-104), Guatemala, desde luego, no fue la excepción 18

Así pues, como ha señalado Marichal (1999, pp. 98-99), para finales del siglo XviII el donativo eran uno de los instrumentos de tipo antiguo que la monarquía utilizaba para recaudar dinero adicional con el cual pagar sus gastos de guerra. Al igual que en Nueva España 19 los donativos levantados en Chiapas entre 1780 y 1814 para financiar el esfuerzo bélico fueron de diversas modalidades. Si bien la mayor parte de estos fueron universales, es decir, que se recaudaron entre todos los sectores que integraban la sociedad (1781, 1793, 1798, 1808 y 1812), otros tuvieron el carácter de particulares pues sólo se solicitaron a grupos específicos de la población (1809 y 1812).

A su vez, estos dos tipos de donativos podían ser voluntarios, es decir, que los causantes elegían libremente contribuir sin que existiera algún mecanismo de coerción que los obligara a hacerlo, o forzosos, esto es, que se coaccionaba a la población para que pagara. Partiendo de estas consideraciones, en las siguientes páginas analizaremos las diversas modalidades de los donativos recaudados en Chiapas entre 1780 y 1814.

\footnotetext{
${ }^{12} \mathrm{Al}$ respecto, véase Fortea (2000, pp. 38-42).

${ }^{13}$ Fondo Diocesano, carp. 4538, exp. 36, f. 1. AHDSC

${ }^{14}$ Diversos análisis sobre los donativos recogidos en España durante los siglos XVI y XVII se encuentra en Fortea (2000), Gil (2015), Lanza (2010) y Truchuelo (2008). Para el caso de los donativos americanos de este periodo se cuenta con el reciente artículo de Nardi (2018).

${ }^{15}$ Guatemala, A3, leg. 1, exp. 1. AGCA.

${ }^{16}$ Guatemala, A3, leg. 1, exp. 7. AGGA.

${ }^{17}$ Guatemala, A3, leg. 367, exp. 4776. AGCA.

${ }^{18}$ Sobre los donativos levantados en Guatemala durante la guerra de sucesión, véase Guatemala, A3, leg. 19, exp. 5247. AGCA.

${ }^{19}$ Las distintas modalidades de los donativos levantados en el virreinato novohispano durante este periodo pueden verse en Marichal (1999, pp. 316-320).
} 


\section{El donativo universal y forzoso de 1780}

Tras el estallido de la guerra anglo-española de 1779-1783, Carlos III pidió a sus vasallos de las Indias contribuir con un donativo para enfrentar a los ingleses en el Caribe, el cual se repartiría de la siguiente forma: los indios y castas libres debían pagar un peso y los españoles y nobles harían lo propio con dos 20

Siete meses después, esta real cédula arribó a Guatemala. Al conocer su contenido, el capitán general, Matías de Gálvez, quien dirigía una campaña militar para expulsar a los ingleses de Omoa (Grafenstein, 2012, p. 124), ordenó que el donativo comenzara a recaudarse en las provincias de la capitanía, para lo cual pidió que los alcaldes mayores, corregidores y gobernadores comisionaran a los tenientes de milicias y a las justicias de los indios para que llevaran a cabo el cobro del donativo entre los habitantes de los pueblos, villas y ciudades del reino ${ }^{21}$

En Chiapas, los alcaldes mayores de Ciudad Real, Cristóbal Ortiz, y de Tuxtla, Luis de Engrava, iniciaron la recaudación del donativo en abril de 1781. A pesar de que varios causantes se resistieron a pagarlo, ya bien ausentándose de sus pueblos durante la recolección, ya bien demorando la entrega de sus contribuciones, en los siguientes dos años la población de la provincia donó aproximadamente 11796 pesos. Es de destacarse que el número de donantes y el dinero recaudado en esta ocasión superó por mucho las cifras alcanzadas en la recolección de los donativos de los años siguientes (1793, 1798, 1808 y 1812). De hecho, 30 años después, al solicitar un nuevo donativo, el capitán general de Guatemala habló de la "agradable memoria que se conserva" del año de 1781 en el cual "apenas hubo individuo que no diese al estado" su donativo ${ }^{22}$

Lo anterior fue posible gracias a dos factores: el primero, fue que el rey impuso la cuota que debía donarse, la cual en el caso de los indios equivalía, aproximadamente, a $40 \%$ del monto que cada año destinaban al pago del tributo y, en segundo lugar, que el donativo se cobró a partir de las matrículas del tributo, por lo cual se ordenó a las justicias de cada pueblo exigir la contribución a todos los indios anotados en ellas, es decir, a poco más de 9000 personas en todo Chiapas (Obara-Saeki y Viqueira, 2017, pp. 505-507).

Aunque esto último aumentó mucho el monto final de la recaudación, también representó un problema en las poblaciones en donde el número de tributarios había disminuido a consecuencia de una reciente epidemia de viruela, pues los indios sobrevivientes tuvieron que pagar los donativos de los fallecidos cuyos nombres no habían sido eliminados del padrón. Por ejemplo, las justicias de Zapaluta dijeron al alcalde mayor que sólo vivían 200 de los 230 indios anotados en la matrícula de su pueblo, razón por la cual ellos tuvieron que completar el dinero faltante ${ }^{23}$

\section{Los donativos universales y voluntarios}

Los conflictos bélicos que cimbraron al mundo atlántico tras el triunfo de la revolución francesa multiplicaron las solicitudes de donativos universales en los territorios americanos de la monarquía española.

\footnotetext{
${ }^{20}$ Fondo Diocesano, carp. 4746, exp. 4, []\{\#_Hlk507358260 San Ildefonso, 17 de agosto de 1780, ff. 1-3. AHDSC.

${ }^{21}$ Fondo Diocesano, carp. 4746, exp. 4, Guatemala, 26 de marzo de 1781, ff. 3-6v. AHDSC.

${ }^{22}$ Fondo Diocesano, carp. 3936, exp. 2. AHDSc.

${ }^{23}$ Fondo Diocesano, carp. 4898, exp. 38, f. 2 . AHDSC.
} 
Para financiar la guerra que España había iniciado contra la Convención que gobernaba Francia (Marichal, 1999, pp. 121-122), en marzo de 1793, el rey, a través de su ministro de Hacienda, Diego Gardoqui, ordenó que las autoridades de los reinos americanos recibieran "las ofertas que los prelados, comunidades de toda especie y cualesquiera otras personas celosas de la religión y de la patria tengan por conveniente hacer" ${ }^{24}$ Pocos años después, en 1796, la monarquía católica emprendió una nueva guerra con Gran Bretaña. En esta ocasión, el bloqueo que los ingleses impusieron sobre Cádiz paralizó el comercio de España con sus reinos americanos y frenó los flujos de plata hacia la península. Para hacer frente al complicado escenario financiero por el que atravesaba el gobierno de Carlos IV, el Ministerio de Hacienda demandó a los habitantes de América la suscripción de un donativo voluntario 25

Durante la crisis dinástica de la monarquía (1808-1814) las autoridades de Guatemala ordenaron directamente la recaudación de estos arbitrios con el propósito de remitir recursos a las tropas que luchaban en la península contra los ejércitos de Napoleón. De este modo, en octubre de 1808, al tener noticia de las abdicaciones de Fernando VII y Carlos IV, y el ascenso al trono español de José Bonaparte, el capitán general de Guatemala, Antonio González, abrió la suscripción a un donativo patriótico voluntario que serviría para financiar "los heroicos esfuerzos de toda España para conservar la religión, salvar el Estado y afirmar un gobierno paternal" 6

El último donativo universal y voluntario del periodo que estudiamos fue solicitado a inicios de 1812 por el capitán general de Guatemala, José de Bustamante ${ }^{27}$ con el fin de cubrir el déficit interno de la Real Hacienda del reino, la cual comenzaba a resentir los efectos de la abolición del tributo de indios y de la suspensión del situado novohispano.

Aunque la corona esperaba que la mayor parte de la población pagara estos donativos, el carácter voluntario de estas contribuciones dio lugar a que en varias ocasiones la mayor parte de los habitantes de Chiapas optara por no pagarlos, argumentando, en casi todos los casos, no disponer de dinero para hacerlo. Así, el donativo de 1793 sólo fue pagado por unos cuantos hacendados de las subdelegaciones del Soconusco y Tuxtla, los ministros de la Caja Real, los conventos de San Francisco de Ciudad Real y Santo Domingo de Chiapas, el obispo Gabriel de Olivares y su Cabildo y algunos españoles, indios y ladinos de Ciudad Real ${ }^{28}$ Por otro lado, en 1808, el párroco de Zinacantán informó que no había extraído ningún donativo de su grey "a causa de la mucha pobreza" de los naturales y ladinos, mientras que el de Huixtán dijo que debido a su miseria los indios de su parroquia "no ofrecían dar nada" 29

Debido a las características demográficas de Chiapas, la mayor parte de los donantes fueron indios. Así, por ejemplo, el donativo de 1781 fue pagado por 9665 naturales, la mayoría de ellos tributarios, y solamente por 500 españoles y ladinos. No obstante, las cantidades donadas por los indios siempre fueron reducidas, por ejemplo, en 1808, el promedio de los donativos individuales de los indios de Salto de Agua fue de tres reales ${ }^{30}$

\footnotetext{
${ }^{24}$ Guatemala, A1, leg. 2210 , exp. 15779, Aranjuez, 30 de marzo de 1793, ff. 1-2. AGCA.

${ }^{25}$ Fondo Diocesano, carp. 4538, exp. 36, Aranjuez 27 de mayo de 1798, ff. 1-2v. AHDSc.

${ }^{26}$ Estado, leg. 24, núm. 220, Guatemala, 19 de octubre de 1808, ff. 1-3. Archivo Histórico Nacional (en adelante AHN).

${ }^{27}$ Fondo Diocesano, carp. 3936, exp. 2, Guatemala, 10 de abril de 1812, f. 2. AHDSC.

${ }^{28}$ Chiapas, A3, leg. 14, exp. 105, Ciudad Real, 28 de abril de 1796, ff. 1-2v. AGCA.

${ }^{29}$ Fondo Diocesano, carp. 4502, exp. 1, ff. 93 y 142. AHDSc.

${ }^{30}$ Fondo Diocesano, carp. 4501, exp. 1, ff. 148-149. AHDSC.
} 
En este sentido, los donativos más cuantiosos provinieron de los hacendados, comerciantes y del clero. Así, los vecinos españoles y ladinos de Tuxtla, muchos de los cuales poseían varias haciendas ganaderas en los valles de Jiquipilas y Cintalapa, cuya producción se vendía en la provincia de Oaxaca o se destinaba a proveer de bestias de carga a los mercaderes que se dirigían hacia ella (Gutiérrez, 2008, p. 658), donaron 882 pesos en 1808 y se comprometieron a seguir contribuyendo hasta que la guerra terminara.

Los donativos de Comitán, en donde un número importante de ladinos y españoles se comenzaba a enriquecer gracias a la prosperidad de la agricultura y la ganadería de su hinterland (Ruz, 1992), también fueron elevados. Así, en 1808, una veintena de hacendados y comerciantes de ese pueblo, algunos de ellos con nexos mercantiles con las casas comerciales más importantes de la ciudad de Guatemala ${ }^{31}$ contribuyeron con un donativo de 607 pesos 32

Por otro lado, en Palenque, en donde residían varios individuos que, al parecer, se beneficiaban enormemente de la posición que el pueblo ocupaba en las redes de contrabando que se extendían desde la laguna del Carmen hasta el occidente de Guatemala ${ }^{33}$ los hacendados donaron 116 pesos en 1798, mientras que a partir de 1808 se comprometieron a erogar 332 pesos anuales para financiar la guerra contra Napoleón 34

La corona también se benefició de los donativos individuales de los miembros del clero. En 1799, los párrocos del obispado de Chiapas y Soconusco donaron 1334 pesos. Los obispos de Chiapas y los integrantes de su Cabildo eclesiástico, aprovechando las porciones de los diezmos que les estaban asignadas, donaron entre 1793 y 1812 alrededor de 3859 pesos. Los conventos de frailes, sobre todo de dominicos y franciscanos, también hicieron contribuciones importantes. Así, el convento de Santo Domingo de Chiapa de Indios donó 200 pesos anuales a partir de 1793 para pagar los gastos de la guerra contra la Convención 35

Aunque la mayor parte de los donativos chiapanecos de este periodo se hicieron en dinero contante y sonante, algunas contribuciones se pagaron en ornamentos y joyas. Este fue el caso de las aportaciones del convento de San Francisco de Ciudad Real, cuya comunidad donó en 1793 varios candelabros y vasijas de oro y plata que al ser subastados por los ministros de la tesorería de la provincia alcanzaron un valor de 270 pesos ${ }^{36}$ Por otro lado, ante la falta de numerario, algunos pueblos optaron por pagar sus donativos en especie, tal es el caso de los indios de la parroquia de Escuintla, quienes se comprometieron en 1812 a donar el producto anual de una milpa 37

En total, los donativos universales recaudados en Chiapas entre 1781 y 1812 aportaron 31128 pesos.

\footnotetext{
${ }^{31}$ Este era el caso de don José Mediano, quien mantenía tratos comerciales con el marqués de Aycinena y figuró como un importante donante (Parrilla, 2017, p. 2; Fondo Diocesano, carp. 4501, exp. 1, Comitán, 3 de enero de 1809, ff. 91-91v. AHDSC).

${ }^{32}$ Fondo Diocesano, carp. 4501, exp. 1, Comitán, 3 de enero de 1809, ff. 91-91v. AHDSC.

${ }^{33}$ Fondo Reservado, doc. 9, ff. 17-18. Archivo Histórico del Estado de Chiapas (en adelante AHEC).

${ }^{34}$ Fondo Diocesano, carp. 4501, exp. 1, Palenque, 18 de noviembre de 1808, ff. 115v-116v. AHDSC.

${ }^{35}$ Chiapas, A3, leg. 14, exp. 105, Ciudad Real, 28 de abril de 1796, f. 1. AGCA.

${ }^{36}$ Guatemala, 800 [Libro Común de la Caja de Chiapas, 1800]. AGI. En el siglo Xvir también fue común que algunos individuos o corporaciones hicieran sus donativos en joyas u ornamentos de oro o plata. Al respecto, véase Nardi (2018, pp. 24-25).

${ }^{37}$ Fondo Diocesano, carp. 3463, exp. 79, Escuintla, 13 de agosto de 1812, f. 1. AHDSC.
} 


\section{El donativo particular y forzoso de 1809}

Pero no todos los donativos eran universales y voluntarios. Al contrario, en algunas ocasiones, estos se recaudaron solamente entre grupos específicos de la población y fueron de carácter forzoso. Un ejemplo de esta modalidad la representa el donativo de 1809 tomado de las cajas de comunidad de los indios de Guatemala.

Convencidos de que la lucha contra Napoleón demandaba muchos recursos y que los habitantes de Guatemala debían seguir contribuyendo con la liberación de la península, el 19 de noviembre de 1808, el capitán general del reino, Antonio González, y los miembros de la Audiencia acordaron donar "a nombre de todos los naturales de las provincias de este reino" 100000 pesos que se tomarían de los sobrantes de las cajas de comunidad 38

Para poder reunir el donativo, las autoridades decidieron prorratear el monto ofrecido entre cada una de las intendencias, alcaldías mayores y corregimientos con base en los ingresos anuales que sus cajas de comunidad percibían. En consecuencia, a los indios de Chiapas les tocó entregar 6284 pesos 39

El 18 de enero de 1809, el contador de propios de Guatemala, Fernando Palomo, comunicó a los intendentes de Chiapas, San Salvador, Comayagua y León que debían trasferir a la Caja de Censos, "en el preciso término de un mes", las existencias depositadas en las cajas de comunidad de sus provincias, "reservando únicamente aquella cantidad que gradúen suficiente para satisfacer los gastos ordinarios situados" sobre estos fondos ${ }^{40}$

Pero la recaudación del donativo enfrentó un problema: las cajas de comunidad del reino carecían del líquido suficiente para erogar la suma que les había sido asignada en el prorrateo. Por ejemplo, el intendente de San Salvador aseguró que el sobrante de las comunidades de su provincia era de 1700 pesos y, por tanto, no alcanzaba para completar su donativo ${ }^{41}$ Asimismo, el intendente interino de Chiapas, José Mariano Valero, informó que le resultaba difícil cumplir con las superiores órdenes pues en el arca de comunidades de Chiapas existían 5468 pesos y cinco reales, es decir, que faltaban 816 pesos para completar la suma requerida como donativo ${ }^{42}$ Como veremos adelante, la falta de liquidez de las cajas de comunidad de Chiapas y del resto de la capitanía se debía a que casi la totalidad de sus sobrantes había sido invertida en la Caja de Consolidación.

Con todo, en los meses siguientes, las autoridades de Guatemala y Ciudad Real consiguieron reunir el donativo que se le había impuesto a los indios de Chiapas. De este modo, completaron el faltante haciendo uso de los ingresos del ramo de tributos 43 y de un capital perteneciente a las cajas de comunidad de la provincia que se encontraba depositado en la Caja de Censos de la ciudad de Guatemala 44

\footnotetext{
${ }^{38}$ Chiapas, A1, leg, 7, exp. 117, Real Audiencia, 13 de noviembre de 1812, ff. 14-15. AGCA. Aunque en algunos documentos este donativo se califica como "voluntario", su carácter fue forzoso, pues la Audiencia, aprovechando sus facultades para decidir el destino que se daba a los sobrantes de las cajas de comunidad, lo impuso sin pedir el parecer de los pueblos del reino.

${ }^{39}$ Los ingresos anuales de las cajas de comunidad de la intendencia de Chiapas ascendían a 7391 pesos. Por ello, las autoridades de Guatemala sólo autorizaron tomar 6284 pesos, de tal forma que los poco más de 1000 pesos restantes se usarían para pagar diversos gastos que estaban asignados a las cajas de comunidad de Chiapas, principalmente el salario de los maestros de escuela.

${ }^{40}$ Guatemala, A3, leg. 16, exp. 344, Guatemala, 18 de enero de 1809, f. 65. AGCA.

${ }^{41}$ Guatemala, A3, leg. 16, exp. 344, San Salvador, 28 de enero de 1809, f. 66. AGCA.

${ }^{42}$ Guatemala, A3, leg. 16, exp. 344, Ciudad Real, 20 de marzo de 1809, f. 77. AGCA.

${ }^{43}$ Chiapas, A1, leg, 7, exp. 117, Real Audiencia, 13 de noviembre de 1812, f. 14. AGCA.

${ }^{44}$ Chiapas, A1, leg, 7, exp. 117, Real Audiencia, 21 de noviembre de 1812, f. 16. AGCA.
} 


\section{El donativo particular y voluntario de 1812}

A diferencia del caso anterior, existieron donativos particulares que no tuvieron carácter de forzosos, sino que fueron voluntarios. Veamos un caso.

Como depositarias de la autoridad soberana ante la ausencia del rey (Guerra, 1992, pp. 124125) las juntas formadas en los reinos peninsulares llegaron a solicitar donativos en nombre de "la causa común" que debía unir a "todos los buenos españoles" para conseguir la "restauración de nuestro suspirado monarca Fernando séptimo", 45 Ante la urgente necesidad de financiar las tropas que luchaban contra el ejército francés, algunos comandantes de la resistencia española, haciendo uso de estas atribuciones, pidieron donativos a sus familiares, amigos o socios en América.

En este sentido, en octubre de 1811, el mariscal de campo Francisco de Espoz y Mina -tío del que años más tarde se convertiría en un célebre caudillo de la guerra de Independencia de Nueva España, Xavier Mina- dirigió una proclama al guatemalteco José de Aycinena en la que le pedía exhortar a sus allegados en la capitanía para que contribuyeran con un donativo voluntario a la lucha que el reino de Navarra sostenía en contra de las tropas de Napoleón 46

Aycinena, quien recibió la proclama con bastante retraso, respaldó la causa de Mina y pidió a varios individuos, entre ellos al obispo de Chiapas, Ambrosio Llano, que suscribieran el donativo y que exhortaran a otras personas a que también lo hicieran, instruyéndoles que el dinero colectado debía remitirse a Julián Bautista Marticorena, vecino de la ciudad de Guatemala, quien se encargaría de enviarlo a la península. Aunque el obispo donó 100 pesos, ningún otro habitante de Chiapas suscribió la contribución para la resistencia navarra ${ }^{47}$

\section{La suscripción patriótica de 1812}

Hacia principios de 1812 la situación financiera del erario de Guatemala se había deteriorado. Para empezar, un año antes, Nueva España suspendió el envío del situado anual de 100000 pesos que permitía a la tesorería del reino cubrir parte de sus erogaciones y, en segundo lugar, la abolición del tributo de indios en 1812 privó a la Real Hacienda de la capitanía de casi la quinta parte de sus ingresos (Wortman, 2012, p. 266).

Para cubrir el déficit del erario, Bustamante ordenó "reformar y economizar todos los gastos que no fueran de primera necesidad", de tal forma que canceló la reparación de la fortaleza de Omoa y el pago a los colonos negros introducidos en esa plaza dos décadas atrás; suspendió la construcción de la catedral y el palacio de gobierno de Nueva Guatemala, y redujo el número de funcionarios civiles y militares (Wortman, 2012, p. 267). Así, en palabras de Bustamante, el erario del reino consiguió ahorrar 100000 pesos durante sus primeros meses de gobierno. 48

Sin embargo, Bustamante comprendió que el déficit del erario amenazaba la estabilidad política del reino, pues la escasez de medios financieros no permitiría al gobierno responder adecuadamente ante un eventual estallido de movimientos subversivos como los que se habían producido en San Salvador y León (Hawkins, 2013, p. 163; Payne, 2013). En este sentido, el capitán general

\footnotetext{
${ }^{45}$ Fondo Diocesano, carp. 4529, exp. 8, Guatemala, 25 de agosto de 1812, f. 2 . AHDSC.

${ }^{46}$ Fondo Diocesano, carp. 4529, exp. 8, Guatemala, 25 de agosto de 1812 . AHDSc. El hecho de que la proclama estuviera dirigida a José de Aycinena y a sus allegados, nos ha hecho considerar a este donativo como particular, pues en ningún momento se buscó extender su recaudación a otros sectores de la población.

${ }^{47}$ Fondo Diocesano, carp. 5156, exp. 67, Guatemala, 3 de abril de 1813 . AHDSC.

${ }^{48}$ Fondo Diocesano, carp. 3936, exp. 2, Guatemala, 10 de abril de 1812, ff- 1-3v. AHDSc.
} 
decretó la recaudación de una contribución extraordinaria que, a pesar de guardar gran similitud con la figura del donativo, estuvo revestida de una serie de particularidades: la suscripción patriótica anual.

Para la recaudación de esta contribución, Bustamante partía del razonamiento de que era "una obligación de consciencia y de justicia la que tenemos todos los naturales y vecinos de América de sostener la lucha". Por ello hacía un llamado a "las primeras clases" y también a "las más escasas de medios" a que contribuyeran, en justa proporción, con la nueva capitación. De esta forma, el objetivo central del capitán general era que los sectores más numerosos de la población del reino, a saber, los indios y los ladinos, colaboraran en el financiamiento del déficit.

En primer lugar, la suscripción era en realidad una estrategia de Bustamante para reimplantar el tributo, aunque ahora como una contribución voluntaria. Este recordó a los indios que se "les ha relevado del antiguo tributo, pero no de la deuda de vasallos", y les pidió contribuir anualmente con dos pesos, es decir, la misma cuota que según la nivelación de 1802 debía pagar un tributario anualmente (Fernández, 2000, pp. 22-30; Pollack, 2016, pp. 103-104). Aunque Bustamante consideraba que la tasa de dos pesos era modesta, abrió la posibilidad para que la aportación de cada pueblo se "prorrateara entre los más pudientes" o se hiciera con el producto de las "siembras de comunidad o de otros arbitrios que en cada lugar proporcionará el celo de los párrocos y justicias".

En el caso de los ladinos, el pago de la suscripción patriótica fue manejada como una especie de licencia para asegurar el goce de las nuevas libertades y derechos del orden político gaditano. De este modo, ante la próxima jura de la Constitución, Bustamante les conminó a contribuir, pues así, dijo, "aumentarán las pruebas" que demostrarían que estaban listos para acceder al "camino de la virtud y del honor" que significaba la ciudadanía de la nación española 49

Así pues, la suscripción patriótica para la guerra se fundamentaba en tres principios que habían sido establecidos por la recién aprobada constitución gaditana: esta tenía un carácter de universalidad (todos los naturales y vecinos de América debemos sostener la lucha en España), de proporcionalidad (en justa proporción debemos soportar una carga que el justo vasallaje nos impone) y de igualdad (darán ejemplo las primeras clases y no se exceptuarán las más escasas de medios) 50

En Chiapas, a diferencia de otras provincias de Guatemala en donde la población indígena se negó a contribuir (Pollack, 2008, pp. 88-89; Wortman, 2012, p. 267), la recaudación de la suscripción de 1812 tuvo un éxito relativo. Así, los indios, ladinos y, en menor medida, los españoles de la provincia hicieron ofrecimientos anuales por valor de 6000 pesos, cifra considerable, aunque sólo representaba la quinta parte del ingreso promedio que había tenido el ramo de tributos, cuya desaparición se buscaba compensar con esta contribución (véase cuadro 2).

\section{LOS PRÉSTAMOS A INTERÉS}

Durante la guerra anglo-española de 1779-1783, la corona comenzó a emitir nuevos tipos de deuda pública que consistían en fincar en calidad de préstamos a interés sobre la Real Hacienda capitales de particulares o de algunas corporaciones civiles y religiosas (Marichal, 1999, p. 99; Valle, 2016, p. 24). Para asegurar la colaboración de la población, se prometía a los accionistas que

\footnotetext{
${ }^{49}$ Fondo Diocesano, carp. 3936, exp. 2, Guatemala, 10 de abril de 1812, f. 3. AHDSC.

${ }^{50}$ Para el caso novohispano, véase Serrano (2007).
} 


\section{GUADRO 2. MONTOS DE LOS DONATIVOS RECOLECTADOS EN CHIAPAS, 1781-1812 (EN PESOS)}

\begin{tabular}{lrr}
\hline Años & Donativos universales & Donativos particulares \\
\hline $1781-1782$ & 11796 & - \\
$1793-1797$ & 3978 & - \\
$1798-1801$ & 3474 & - \\
$1809-1811$ & 7556 & 6284 \\
$1812-1813$ & 4324 & 100 \\
\hline
\end{tabular}

Fuente: Fondo Diocesano, carp. 4362, exp. 13; carp. 3464, exp. 46 y carp. 4271, exp.14, AHDSC; Guatemala, 800, AGI.

las rentas del erario, principalmente la de alcabalas y del tabaco, cubrirían los réditos anuales que sus depósitos devengaran, que por lo general iban de 3 a $5 \%$, y amortizarían la deuda en el plazo acordado.

Aunque el gobierno de Carlos III limitó las emisiones de deuda pública (Torres, 2008, pp. 427435), la bancarrota de la Real Hacienda durante el reinado de Carlos IV obligó a la corona a multiplicar las solicitudes de préstamos a interés a sus vasallos americanos. En este sentido, en las páginas que siguen buscaremos estudiar la composición y los montos de la deuda pública reconocida por la caja de Chiapas. Antes de avanzar es preciso señalar que la deuda pública que abordaremos en este trabajo está compuesta por aquellos adeudos gravoso $\$ 1$ que el erario contrajo mediante el depósito a censo redimible de las obras pías del obispado (1782), el préstamo patriótico de 1798 (1798-1801), la Consolidación de Vales Reales (1805-1808) y el ramo del real empréstito $(1809-1813) 52$

\section{El depósito a censo redimible de las obras pías del obispado de 1782}

El 17 de agosto de 1781, Carlos III dirigió una real cédula a sus virreyes, capitanes generales y obispos de las Indias en la cual ordenó que todos los caudales líquidos pertenecientes a vínculos, patronatos, mayorazgos, capellanías, obras pías y cualquier otra fundación -a los que definía como "unos capitales que se hallaban como muertos"- se tomaran a censo redimible a cuenta de la Real Hacienda, hipotecando como garantía para los acreedores la renta del tabaco y prometiéndoles una tasa anual de utilidades de 4 por ciento 53

\footnotetext{
${ }^{51}$ En este sentido, retomamos la metodología propuesta por Ernest Sánchez (2016a,) para abordar la deuda pública contraída por la Tesorería General de Ejército y Real Hacienda de la Nueva España, la cual considera como deuda aquellos "ramos que son gravosos al erario por ser reintegrables". Esta acotación es importante pues, como demuestra este autor, las cajas reales reconocían una serie de ramos conformados por préstamos "que no generaban una verdadera deuda para la corona, ya que su origen estaba en ramos del erario regio o se hallaban en ramos particulares y ajenos que exigen reintegros y no el reintegro de los fondos" (Sánchez, 2016a, pp. 39-43).

${ }^{52} \mathrm{El}$ peso de la política de endeudamiento que la corona implementó recayó sobre dos sectores de la población de Chiapas: la Iglesia y los pueblos de indios. La participación de hacendados o comerciantes chiapanecos como suscriptores de los préstamos a interés para la corona fue escasa. Solamente en 1799, tres vecinos de Palenque y tres de Tapachula invirtieron 146 pesos en el préstamo solicitado un año atrás por el rey. Guatemala 800 [Libro Común de la Caja de Chiapas, 1800]. AGI.

${ }^{53}$ Fondo Diocesano, carp. 4566, exp. 20, San Ildefonso, 17 de agosto de 1780. AHDsc. En la península la tasa de utilidades había sido de tres por ciento.
} 
Aunque esta real cédula no tuvo respuesta por parte del clero de Nueva España (Valle, 2016, pp. 52-53; 160-161), en Guatemala las catedrales sí acataron la orden del rey. Así, el capitán general, Matías de Gálvez, solicitó al obispo de Chiapas informar sobre los capitales de capellanías u obras pías depositados en las arcas de la catedral. Tras averiguar sobre el asunto, se supo que estaban disponibles los principales de 19 fundaciones que juntas sumaban un total de 14850 pesos. En consecuencia, el 12 de noviembre de 1782 este dinero fue entregado a la Real Hacienda $\sqrt[54]{6}$

Como establecían las órdenes reales, la obligación de pagar los réditos, en este caso a los capellanes que rezaban las misas de las fundaciones, corrió a cargo de la administración del tabaco de Guatemala, la cual encargó a la Factoría de Ciudad Real esta tarea. La documentación existente nos permite observar que la Factoría tardó casi 20 años en devolver ese capital a las arcas de la catedral de Chiapas. Así, el 29 de enero de 1803 el director general de la renta en Guatemala ordenó al factor de Ciudad Real, Luis Martínez Trujillo, amortizar los 14850 pesos depositados a censo en 1782. Sin embargo, el factor señaló que los caudales sobrantes de su oficina ascendían únicamente a 4800 pesos, por lo cual sólo redimió los principales de unas cuantas fundaciones 55

\section{El préstamo patriótico de comunidades de indios de 1801}

El 20 de mayo de 1798, la corona emitió una real cédula en donde pidió a sus vasallos americanos suscribir un empréstito para cubrir los gastos de la guerra contra Inglaterra. El empréstito, que sería reconocido como deuda nacional, constaría de un número limitado de acciones, cada una con valor de 31 pesos y cuatro reales, las cuales podrían ser adquiridas "hasta por las personas menos acomodadas" 56

En respuesta a esta real cédula, el 8 de enero de 1799 los ministros de la Audiencia de Guatemala autorizaron prestar a la corona tres cuartas partes de los sobrantes de las cajas de comunidad de los indios del reino, prometiendo pagar un rédito anual de $5 \%$ o "el premio [que la Real Hacienda] tenga por conveniente asignar" ${ }^{57}$ Así, aunque las reales órdenes indicaban que el préstamo patriótico se haría sin intereses (Sánchez, 2016a, p. 46), en la capitanía de Guatemala se ofrecía a los indios una utilidad anual.

En los meses siguientes, las cajas de comunidad de varios pueblos de las intendencias de León, Comayagua y San Salvador trasladaron a las arcas del erario poco más de 69000 pesos $\sqrt{58}$ Sin embargo, las autoridades decidieron que los sobrantes de las cajas de comunidad de Chiapas debían mantenerse en reserva en espera de que la corona demandara más recursos para la guerra.

En este sentido, el 7 de septiembre de 1801, el capitán general, Antonio González Mollinedo, informó a los ministros de Real Hacienda que los comandantes del Petén y Omoa, así como los intendentes de Comayagua y León, tras enterarse de la presencia de naves enemigas en las costas de sus provincias, le solicitaron que enviara las remesas necesarias para la defensa de esos territorios. Si bien los ministros de Real Hacienda dijeron poder satisfacer las demandas de las dos primeras plazas, indicaron que no había caudales suficientes para auxiliar a Comayagua y León, y, por tanto,

${ }^{54}$ Fondo Diocesano, carp. 3712, exp. 9, Ciudad Real, 12 de noviembre de 1782. AHDSC.

${ }^{55}$ Fondo Diocesano, carp. 3712, exp. 17, Ciudad Real, 11 de febrero de 1803, f. 1. AHDSc. El resto del dinero se devolvió en 1805. Sin embargo, la Junta de Consolidación de Ciudad Real lo enajenó inmediatamente.

${ }^{56}$ Según lo dispuesto, las suscripciones se cerrarían en la península el 31 de diciembre de ese año y en las Indias el 30 de junio del próximo y se prometió a los accionistas que su dinero les sería devuelto en diez años, pasando dos de la finalización de la guerra. Fondo Diocesano, carp. 4538, exp. 36. AHDSc.

${ }^{57}$ Chiapas, A3, leg, 335, exp. 4362, Real Palacio, 17 de septiembre de 1801, ff. 3v-4. AGCA.

${ }^{58}$ Guatemala, A3, leg. 14, exp. 292. AGCA. 
sugirieron a Mollinedo tomar 50000 o 60000 pesos de las cajas de comunidad de los pueblos de la intendencia de Ciudad Real que, según la resolución de la Audiencia, podían suscribirse al préstamo para el rey 59

De inmediato, el capitán general ordenó a los ministros de la tesorería de Chiapas dar a conocer del monto de los sobrantes de las cajas de comunidad para que dedujeran las tres cuartas partes que debían ser entregadas a la Real Hacienda. Respondiendo a la solicitud, el contador y el tesorero de Ciudad Real informaron que en total existían en el arca de comunidades de la provincia 62820 pesos con seis reales, de tal forma que las tres cuartas partes ascendían a 47115 pesos con cinco reales y un cuartillo ${ }^{60}$ El préstamo se realizó el 26 de octubre de ese año.

Sin embargo, el destino que se estaba dando al dinero infringía las órdenes dadas desde España para el manejo de los capitales que se suscribieran al empréstito patriótico, pues si bien la real cédula de mayo de 1798 establecía que los capitales suscritos a esta operación debían remitirse a la península ${ }^{61}$ las autoridades guatemaltecas estaban utilizando este dinero en las fortificaciones que defendían los puertos del reino, es decir, en cubrir un gasto militar interno.

$\mathrm{Al}$ enterarse de ello, Cayetano Soler, ministro de Hacienda de Carlos IV, ordenó a González Mollinedo devolver los 47115 pesos y le prohibió pagar los réditos de $5 \%$ prometidos a los indios por ser gravosos a la Real Hacienda 62 Aunque la devolución de este capital se completó entre 1804 y 1807, el dinero no permaneció mucho tiempo en la provincia pues fue trasferido a la Caja de Consolidación de Guatemala.

\section{La Consolidación de Vales Reales}

Hacia finales de 1804 las autoridades metropolitanas decidieron extender la Consolidación de Vales Reales a América. Como ha sido señalado por Carlos Marichal (1995, pp. 243, 251), la aplicación de esta medida en los reinos americanos obedece fundamentalmente a la necesidad de los ministros de Hacienda de la corona por remediar la grave crisis financiera del gobierno de Carlos IV, la cual adquirió proporciones catastróficas a consecuencia de la devaluación de los títulos de la deuda pública - los vales reales-, la firma del Tratado de Suministros con Francia y el estallido de la segunda guerra naval contra Gran Bretaña (Wobeser, 2003, pp. 27-50).

En este sentido, el decreto y la instrucción para la enajenación de obras pías en América establecían que debían depositarse en la Caja de Consolidación los capitales y el producto de la venta de las propiedades del clero, exceptuando los bienes dotales de las comunidades religiosas, con la promesa de que a los individuos y corporaciones afectados se les pagaría un interés anual de $5 \%$, que quedaría asegurado con la hipoteca de las rentas de tabacos y alcabalas 63

En Guatemala la aplicación de la ley de consolidación comenzó en mayo de 1805 con la formación de la Junta Superior de Consolidación del reino ${ }^{64}$ y un mes después la ley comenzó a aplicarse en el obispado de Chiapas y Soconusco 65 Así, la Junta Subalterna de Consolidación de

\footnotetext{
${ }^{59}$ Chiapas, A3, leg, 335, exp. 4362, Real Palacio, 7 de septiembre de 1801, f. 1. AGCA.

${ }^{60}$ Chiapas, A3, leg, 335, exp. 4362, Ciudad Real, 21 de octubre de 1801, f. 10. AGCA.

${ }^{61}$ Fondo Diocesano, carp. 4538, exp. 36, Aranjuez 28 de mayo de 1798, artículo VII. AHDSC.

62 AGCA, Chiapas, A3, leg. 335, exp. 4362, Guatemala, 23 de noviembre de 1802, ff. 18-19. AGCA.

63 Ambos documentos se encuentran publicados en Wobeser (2003).

${ }^{64}$ Guatemala, A3, leg. 2759, exp. 39747, Guatemala, 27 de mayo de 1805, f. 1. AGCA.

${ }^{65}$ Fondo Diocesano, carp. 3844, exp. 2, Ciudad Real, 15 de junio de 1805, f. 4. AHDSC.
} 
Ciudad Real, la cual estaba integrada por el intendente, el obispo y un teniente diputado, procedió a solicitar a las diversas corporaciones del clero que informaran sobre los capitales líquidos y propiedades que tuvieran en su poder, y que dieran una relación detallada de los individuos a los cuales habían otorgado censos perpetuos y a depósito irregular.

Aunque una parte del clero chiapaneco, principalmente los dominicos, se opuso veladamente a la medida, demorando todo lo posible la entrega de la información solicitada o entregándola con una serie de errores encaminados a entorpecer su aplicación 66 en el trascurso de los siguientes tres años la junta subalterna de Chiapas enajenó 81581 pesos provenientes de varios depósitos de capellanías, obras pías y dotes de monjas que eran administrados por el juzgado de la catedral, los conventos de Santo Domingo, San Francisco, la Merced y la Encarnación de Ciudad Real, y algunas parroquias del obispado como las de Comitán, San Bartolomé y Tapachula. Menos afectadas resultaron las cofradías de españoles y ladinos, y las escuelas e instituciones de auxilio social (como el hospital de San Juan de Dios de Ciudad Real) que eran administradas por la Iglesia.

Todo indica que los efectos de la consolidación sobre la riqueza de la Iglesia chiapaneca fueron limitados. Así, la junta subalterna de Ciudad Real no consiguió que la mayor parte de los individuos que tenían en su poder capitales del clero en calidad de préstamo redimieran sus deudas, de tal forma que solamente recuperó 60000 de los poco más de 380000 pesos que las diversas corporaciones eclesiásticas de provincia tenían invertidos en censos perpetuos y a depósito irregu$\operatorname{lar} 67$

Además, como ocurrió en otras regiones de Nueva España (Wobeser, 2003, pp. 70-71), la consolidación fracasó al poner en venta las propiedades del clero chiapaneco. Ello obedeció a que los dominicos, quienes eran los principales terratenientes eclesiásticos del obispado, demoraron demasiado en entregar la información sobre sus haciendas, y a que la Junta de Ciudad Real no encontró sujetos capaces de adquirirlas, pues, paradojas de la vida, la misma consolidación cortó las fuentes de crédito que hubieran permitido a los interesados comprar estas propiedades 68

En vista de lo complicado que resultaba enajenar la riqueza de la Iglesia, los miembros de la junta de Chiapas optaron por dirigir los efectos de la consolidación hacia unos fondos sobre los que ejercían mayor control: las cajas de comunidad de los indios.

\footnotetext{
${ }^{66}$ La información sobre la resistencia de los dominicos y algunos párrocos del obispado se encuentra en Fondo Diocesano, carp. 5132, exp. 1. AHDSc.

${ }^{67}$ Esta información se desprende de un informe elaborado por la Junta subalterna de Ciudad Real en donde se mostraba que el clero, sin contar a los conventos dominicos, tenía invertidos más de 380000 pesos en diversos préstamos que estaban en poder de más de un centenar de individuos que vivían dentro del territorio del obispado o en provincias vecinas de Guatemala, como Quetzaltenango, y de Nueva España, principalmente en Tabasco (Fondo Diocesano, carp. 3724, exp. 4. AHDSC). Sin embargo, la contabilidad generada por la junta revela que no fue posible hacer que todos los deudores, ni siquiera la mayor parte, redimieran sus deudas, por lo cual hemos calculado que sólo se lograron recuperar 60000 de 380000 pesos que se hallaban invertidos en el mercado de crédito de las corporaciones religiosas del obispado. Al respecto, véase Chiapas, A3, leg, 234, exp. 2899. AGCA.

${ }^{68}$ De hecho, el mismo capitán general reconoció que sería muy difícil que alguien pudiera reunir los capitales para comprar las haciendas del clero (Ruz, 1992, pp. 285-286), opinión que resultó ser acertada, pues finalmente la junta superior del reino señaló que habían sido “muy pocos [los remates de haciendas] que han ocurrido”. Estado, 57 C, exp. 7, Guatemala, 20 de agosto de 1808, f. 1. AHN.
} 
Aunque la instrucción para el cumplimiento de la real cédula de Consolidación, dada en Madrid el 26 de diciembre de 1804, eximía a las cofradías de indios de la amortización de sus principales, el artículo 14 de dicho documento autorizaba a los miembros de las juntas superiores de consolidación de los reinos americanos a trasladar parte de los sobrantes de las cajas de comunidad de indios a las arcas de la consolidación (Wobeser, 2003, p. 162).

En vista de ello, los miembros de la Audiencia de Guatemala ordenaron que tres cuartas partes de los sobrantes de las cajas de comunidad de los indios y ladinos del reind ${ }^{69}$ se trasfieran a la Caja de Consolidación esgrimiendo el argumento de que esta inversión beneficiaría a los pueblos "por la seguridad con que se conservarán [sus fondos] como por el aumento que producirán [a sus erarios] los réditos que deberán satisfacerles" 70

En consecuencia, el 10 de junio de 1805, 41780 pesos de las cajas de comunidad de Chiapas fueron pasados al arca de consolidación, y años después, en julio de 1807, otros 31725 pesos de estos mismos fondos fueron enajenados por órdenes de la Audiencia ${ }^{71}$ Finalmente, en octubre de ese año, la Real Hacienda reintegró al fondo de comunidades de Chiapas los últimos 24143 pesos del préstamo hecho por los indios en 1801. En vista de que este dinero pasaba a convertirse en sobrante, las autoridades de Guatemala decidieron que también debía transferirse al arca de consolidación, con la finalidad "de que dichos caudales reditúen a beneficio de los pueblos de esta provincia"72

Cuando la consolidación fue suspendida en Guatemala en agosto de $1808{ }^{73}$ los indios de Chiapas habían invertido en ella 97648 pesos. Esta cifra representó 54 \% de los capitales enajenados en la provincia, los cuales ascendieron a 179229 pesos. ${ }^{74}$

\section{El real empréstito de 1809}

En mayo de 1809, el virrey interino de Nueva España, el arzobispo Francisco Xavier Lizana, ordenó publicar en la Gaceta de México una real orden dirigida por la junta suprema de España a los habitantes de ese reino en donde promovía la suscripción a un empréstito para subvenir los gastos de la guerra contra Napoleón. Al enterarse de ello, la Audiencia de Guatemala decidió que la recolección del real empréstito debía extenderse a la capitanía 75

\footnotetext{
${ }^{69}$ Hasta donde hemos podido averiguar, sólo existían cajas de comunidad de ladinos en las provincias de San Salvador y Escuintla. Guatemala, A3 leg. 1493, exp. 24700. AGCA.

${ }^{70}$ Guatemala, A3 leg. 1493, exp. 24700, Guatemala, 10 de julio de 1805, f. 2. AGCA.

${ }^{71}$ Guatemala, A3, leg. 16, exp. 344, Ciudad Real, 21 de julio de 1807, f. 6. AGCA.

${ }^{72}$ Chiapas, A3, leg. 335, Ciudad Real, 29 de agosto de 1807, f. 1. AGCA.

${ }^{73}$ Tras conocer que la enajenación de bienes y capitales píos había sido suspendida en Nueva España (Valle, 2012, p. 203), la Junta Superior de Consolidación de Guatemala decidió secundar esta decisión y ordenó a las juntas subalternas del reino suspender temporalmente sus labores a la espera de recibir la orden de la suspensión definitiva por parte de las autoridades metropolitanas (Estado, 57C, exp. 7, Guatemala, 20 de agosto de 1808. AHN). Finalmente, en septiembre de 1809, arribó a Guatemala el decreto de la Junta Suprema de España en donde se cancelaba la Consolidación de Vales Reales en toda la monarquía (Fondo Diocesano, carp, 4538, exp. 15. AHDSC).

${ }^{74}$ Guatemala, A1, leg. 221, exp. 5197, Guatemala, 3 de agosto de 1809, f. 4v. AGCA.

${ }^{75}$ Guatemala, A1, leg. 221, exp. 5197, México, 5 de agosto de 1809, ff. 9-11. AGCA.
} 
De este modo, la primera medida decretada por el capitán general para dotar de fondos al ramo del real empréstito consistió en solicitar a la Iglesia que invirtiera en él los capitales que no habían sido absorbidos por la Caja de Consolidación, con la promesa de que se le pagarían réditos anuales de $4 \%$ hasta que su dinero le fuera devuelto -en Nueva España se había ofrecido un premio de $6 \%$ (Sánchez, 2016a, p. 47) 76

Debido a que la consolidación estuvo lejos de consumir toda la riqueza de la Iglesia en Chiapas, algunas corporaciones religiosas reaccionaron positivamente al llamado de la Audiencia y comenzaron a negociar con las autoridades de la provincia las tasas de interés de los capitales que prestarían, así como los plazos de amortización de estos, los cuales oscilaron entre cinco y 25 años. En consecuencia, entre 1809 y 1811 , el Cabildo eclesiástico, el juzgado de Capellanías, el convento de San Francisco, el convento de la Encarnación, la parroquia de Huehuetán y el Colegio Seminario transfirieron al ramo del real empréstito 14436 pesos.77

Sin embargo, las contribuciones del clero fueron insuficientes ante la gravedad de la crisis en la península. Debido a ello, el 29 de agosto de 1809, la Audiencia de Guatemala, "teniendo en consideración que de los fondos de comunidad puede hacerse algún empréstito considerable para un objeto tan sagrado”, ordenó a la Contaduría de Propios que formara un estado de los sobrantes depositados en las cajas de comunidad y evaluara la pertinencia de trasferir una parte de estos al empréstito. 78

En su informe, la contaduría mostró que las cajas de comunidad del reino se encontraban "tan exhaustas" por las trasferencias que habían realizado a la Caja de Consolidación, que disponían de muy pocos recursos para ser invertidos en el real empréstito. En el caso de la intendencia de Ciudad Real, por ejemplo, el informe mostraba que los sobrantes de las cajas de comunidad ascendían a 7623 pesos 79

A pesar del estado miserable en el que se hallaban los erarios indios, las autoridades de Guatemala ordenaron al intendente y los ministros de Real Hacienda de Chiapas que transfirieran al ramo del real empréstito 4964 pesos de estos fondos prometiendo una utilidad anual de $5 \% 80$ Con esta inversión las cajas de comunidad de Chiapas quedaron prácticamente agotadas, pues en ellas solamente quedó una existencia de 2659 pesos. Sin embargo, en los años siguientes, las autoridades de Guatemala, agobiadas por el creciente déficit del erario, continuarían transfiriendo parte de estos recursos a las arcas reales.

Como vimos, a partir de 1812 las finanzas de Guatemala comenzaron a deteriorarse debido a la suspensión del situado novohispano, la abolición del tributo de indios. Simultáneamente, la necesidad de recaudar más recursos para la defensa del reino aumentó cuando la insurgencia mexicana comandada por Morelos se apoderó de la intendencia de Oaxaca. Esta situación alarmó a las autoridades de Chiapas, pues temieron que los insurgentes invadieran la provincia. En vista de la amenaza que representaba el ejército de Morelos, el intendente de Ciudad Real, Manuel Junguito, pidió al obispo Llano que "para la subvención a los enormes gastos que se están

\footnotetext{
${ }^{76}$ Fondo Diocesano, carp. 4538, exp. 15. AHDSC.

${ }^{77}$ Guatemala, A3, leg. 283, exp. 6031 y AGCA, Guatemala, A3, leg. 2350, exp. 34581. AGCA.

${ }^{78}$ Guatemala, A1, leg. 221, exp. 5197, Guatemala, 29 de agosto de 1809, ff. 1-1v. AGCA.

${ }^{79}$ Guatemala, A1, leg. 221, exp. 5197, Guatemala, 31 de agosto de 1809, ff. 5v-6. AGCA.

${ }^{80}$ Guatemala, A3, leg. 16, exp. 344, Ciudad Real, 30 de octubre de 1809, ff. 88-89v. AGCA.
} 
impendiendo en el mantenimiento" de las tropas que comenzaban a enviarse a "la raya del reino mexicano", procediera a trasladar al ramo del real empréstito los caudales guardados en la Clavería de la catedral 81

Tras recibir el oficio, el obispo mandó a los encargados de la Clavería a hacer el informe de los capitales a su resguardo ${ }^{82}$ En pocos días, se tuvo noticia de que los fondos disponibles para el préstamo ascendían a 6000 pesos. Sin embargo, Llano se mostró inconforme con que los depósitos píos administrados por la Iglesia siguieran sirviendo para cubrir erogaciones militares. Molesto, hizo saber al intendente que, aunque se sentía preocupado por la cercanía del ejército de Morelos, consideraba que continuar echando mano de los capitales del clero atentaba contra el orden que imponía la recién jurada Constitución de Cádiz, pues: "está entredicho todo lo que huele a arbitrariedad, desigualdad de cargas, contribuciones y depresiones de la propiedad individual de todo español y corporación capaz de bienes temporales" 83

El cuestionamiento que el obispo hacía a la autoridad de Junguito para imponer el préstamo apelaba a uno de los principales principios garantista de la nueva Carta Magna, pues esta determinaba que "la única autoridad capacitada para aprobar o derogar contribuciones o contraer préstamos serían las Cortes Generales” (Sánchez, 2015, pp. 136-137). De inmediato, el intendente respondió al prelado que, en tiempos de guerra, "la costumbre de realizar dicha traslación tiene fuerza como ley", por lo cual dio luz verde a al traslado del dinero a la Hacienda pública (véase gráfica 1) 84

Este incidente evidencia que la tesorería de Chiapas comenzaba a padecer un problema similar al que por esas mismas fechas aquejaba a otros erarios provinciales de Nueva España, como el yucateco: el crédito para la Hacienda pública comenzaba a agotarse como consecuencia del cansancio que padecía una parte de la sociedad ante la presión ejercida a través de la fiscalidad extraordinaria en los años anteriores ${ }^{85}$ Además, es casi seguro que la suspensión del servicio de la deuda (de ello hablaremos adelante) influyó en la inconformidad del obispo sobre seguir transfiriendo el dinero administrado por la Iglesia a las arcas del erario.

El agotamiento del crédito llegó en un mal momento. Aunque el capitán general de Guatemala ordenó al comandante de la columna militar enviada a Chiapas, Manuel Dambrini, permanecer dentro de los límites de la intendencia, este decidió penetrar la provincia de Oaxaca. Si bien en sus primeras campañas logró retomar el control de varias poblaciones en el istmo de Tehuantepec, sus tropas carecían de suficientes pertrechos para continuar la avanzada, por lo que decidió regresar a Chiapas. Sin embargo, en medio del repliegue una columna insurgente dirigida por Mariano Matamoros les dio alcance y se batió en combate contra ellos en las cercanías de Tonalá el 19 de abril de 1813. Aunque la refriega duró pocos días, y terminó con la victoria de los rebeldes, Matamoros decidió regresar a Oaxaca.

\footnotetext{
${ }^{81}$ Además, el intendente pidió al obispo que si tenía noticia de "cualquier otro capital que se halle en personas particulares” lo informara para que también se viera la forma de trasladarlo a las arcas de la Hacienda pública. Fondo Diocesano, carp. 4511, exp. 4, Ciudad Real, 27 de febrero de 1813, f. 9. AHDSC.

${ }^{82}$ Fondo Diocesano, carp. 4511, exp. 4, Ciudad Real, Ciudad Real, 1 de marzo de 1813, f. 9. AHDSG.

${ }^{83}$ Fondo Diocesano, carp. 4511, exp. 4, Ciudad Real, 20 de marzo de 1813, f. 6 . AHDsc.

${ }^{84}$ Fondo Diocesano, carp. 4511, exp. 4, Ciudad Real, 21 de marzo de 1813, f. 7. AHDSC.

${ }^{85}$ Para el caso de la Real Hacienda de Yucatán, para la cual las fuentes de crédito comenzaron a agotarse durante la coyuntura de insolvencia que vivió ese erario a causa de la crisis dinástica de la monarquía y la insurgencia novohispana, véanse Quezada y Moreno (2005, p. 328) y Sánchez (2012, p. 343).
} 


\section{GRÁFICA 1. EVOLUCIÓN DEL MONTO DE LA DEUDA PÚBLICA EN CHIAPAS, 1782-1814}

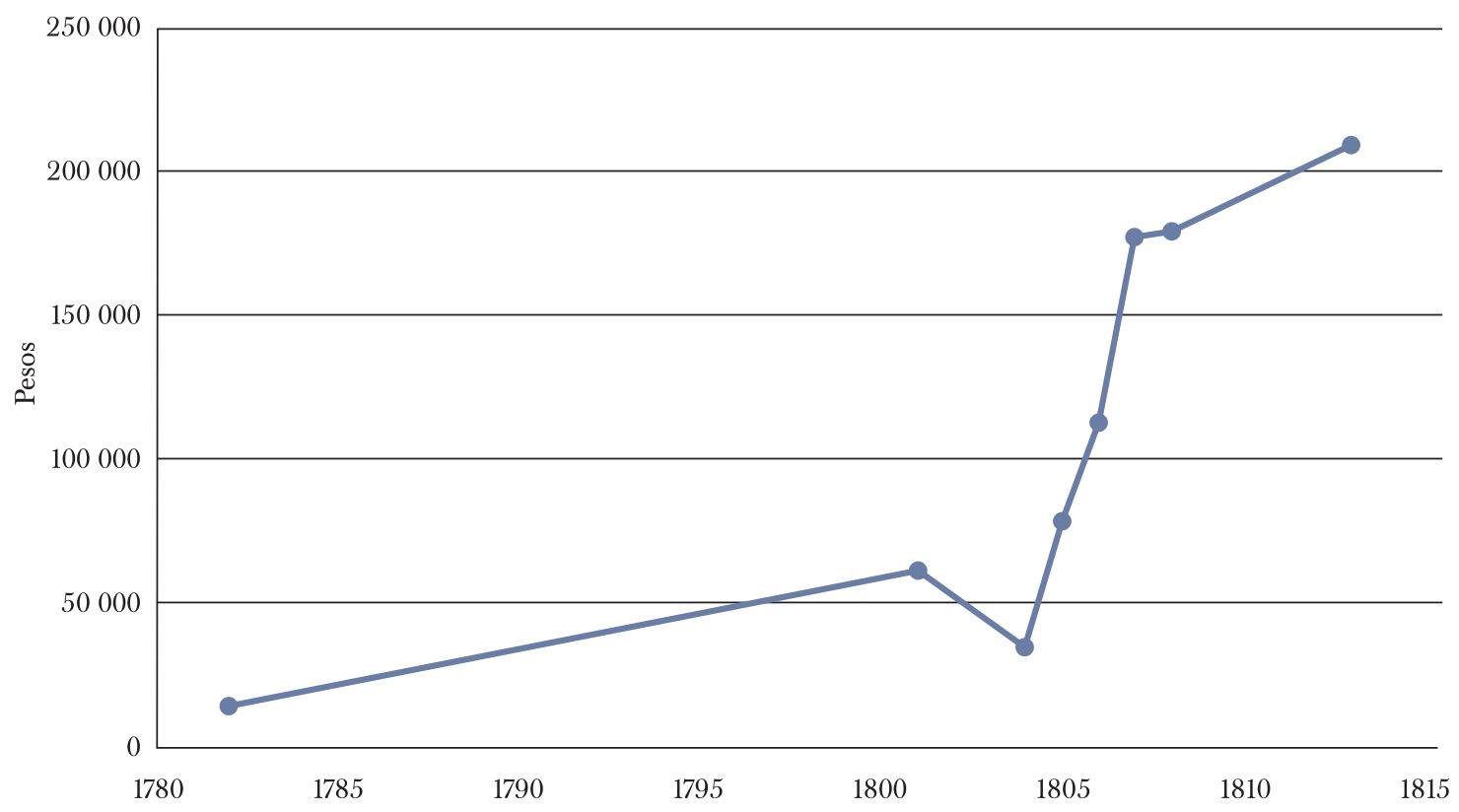

Nota: la disminución que se nota en el monto de la deuda entre 1801 y 1805 obedece a que la Factoría del Tabaco de Ciudad Real amortizó 4800 pesos de la deuda que mantenía con la catedral desde 1782 y a que la Real Hacienda devolvió a las cajas de comunidad 22972 pesos del préstamo de 1801. A partir de 1805 el monto de la deuda comienza a elevarse como resultado de la aplicación de la Consolidación de Vales Reales y, posteriormente, de la apertura del ramo del real empréstito en 1809.

Fuente: Fondo Diocesano, carp. 3712, exp. 9 y carp. 4366, exp. 2, AHDSC. Chiapas, A3, leg. 335, exp. 4362, y Guatemala, A1, leg. 221, exp. 5197, AGCA.

En vista de estos sucesos, las autoridades del reino temieron que el ejército de Morelos respondiera con una invasión a Guatemala, por lo cual reforzaron la presencia militar en Chiapas en los meses posteriores a los combates de Tonalá. Sin embargo, el aumento en el número de tropas en la provincia incrementó los gastos de la Hacienda pública de Ciudad Real, la cual tuvo que costear los salarios y los gastos de manutención de los soldados. El problema para las autoridades de Chiapas era que los ingresos del erario habían disminuido bastante tras la abolición del tributo de indios.

Desesperado por conseguir recursos con los cuales pagar la manutención de los soldados, el intendente Junguito buscó tomar en calidad de préstamo parte del dinero de los diezmos de la catedral, a lo cual, evidentemente, se opuso el obispo Llano ${ }^{86}$ Tras este infructuoso intento, el intendente pidió al contador de propios del reino, Fernando Palomo, su autorización para tomar en calidad de préstamo de los sobrantes de las cajas de comunidad de la provincia con el fin de invertirlos en las erogaciones militares 87

${ }^{86}$ Fondo Diocesano, carp. 2537, exp. 1, Macuilapa, 21 de julio de 1813, f. 1. AHDSC.

${ }^{87}$ Chiapas, A3, leg. 336, exp. 4372, Macuilapa, 15 de julio de 1813, ff. 2-3. AGCA. 
Tras consultar los estados de las cuentas de las cajas de comunidad de Chiapas, el contador determinó que el monto máximo al que podía ascender el préstamo era de 4000 pesos ${ }^{88}$ y aclaró que, dada la escasez de fondos de la Hacienda pública, no podía fijar un plazo para la devolución de este capital por lo que indefinidamente se pagaría a los naturales "un premio de $5 \%$ anual".

Con todo, la temida invasión de la insurgencia novohispana jamás se llevó a cabo y el retorno de Fernando VII al trono de España permitió el restablecimiento del tributo con lo cual la salud de la tesorería de Ciudad Real mejoró. Para esas fechas, la corona había contraído una deuda con los pueblos indios y la Iglesia de Chiapas que ascendía a 208628 pesos. En los años siguientes, la tesorería de Chiapas enfrentó el reto de cubrir las utilidades de la deuda, que ascendían a 10226 pesos por año ${ }^{89}$ y comenzar a devolver los capitales de plazo vencido que habían sido depositados en el ramo de real empréstito.

\section{El servicio de la deuda}

Los pagos del servicio de la deuda pública contraída en Chiapas pueden dividirse en tres periodos. El primero, que va de 1803 a 1811, se caracterizó por el reintegro de los capitales prestados a la corona entre 1782 y 1801 . A partir de 1803 comenzó la amortización de los 14850 pesos que la catedral depositó en la Real Hacienda veinte años atrás para pagar la guerra contra Gran Bretaña 90 y entre 1804 y 1807 se devolvieron 47000 pesos que las cajas de comunidad transfirieron al préstamo patriótico ${ }^{91}$ A partir de este último año comenzaron a pagarse las primeras utilidades de los capitales ingresados a la Caja de Consolidación, de tal forma que este gasto pasó de 222 pesos en 1807 a 3409 en 1811 (véase cuadro 3).

El segundo periodo se desarrolló durante la etapa más álgida de la crisis imperial en Chiapas: 1812-1814. Durante estos años, la disminución de los ingresos de la caja provincial (por la abolición del tributo) y el aumento en los gastos militares (debido a la necesidad de mantener a la tropa apostada en la "raya de México") impidieron a las autoridades de la Hacienda pública cubrir el servicio de la deuda, por lo cual los réditos de la consolidación y el real empréstito dejaron de pagarse 92

Tras el restablecimiento del absolutismo inició el tercer periodo. A partir de 1814, las finanzas de la caja provincial mejoraron a medida que los subdelegados consiguieron que los indios pagaran el tributo (véase cuadro 1). Además, en 1817 estos elaboraron nuevas matrículas que arrojaron un aumento en el número de tributarios por lo cual los ingresos del erario se vieron favorecidos en el

\footnotetext{
${ }^{88}$ Chiapas, A3, leg. 336, exp. 4372, Guatemala, 17 de agosto de 1813, f. 4. AGCA.

${ }^{89}$ Las utilidades de $5 \%$ anuales que generaban 179229 pesos ingresados a la Caja de Consolidación ascendían a 8961 pesos. Los 20435 pesos invertidos por la Iglesia con una tasa de $4 \%$ al ramo del real empréstito generaban un interés anual de 817 pesos y, por último, los 8964 pesos trasladados de las cajas de comunidad a este mismo ramo, a una tasa de $5 \%$, generan anualmente réditos por valor de 448 pesos. En total, pues, la caja de Ciudad Real debía pagar a sus acreedores 10226 pesos a partir de 1814 .

${ }^{90}$ Fondo Diocesano, carp. 3712, exp. 17, Ciudad Real, 11 de febrero de 1803, f. 1. AHDSc.

${ }^{91}$ Chiapas, A3, leg. 335, exp. 4362, f. 23. AGCA.

${ }^{92}$ De hecho, desde 1809 se había propuesto dejar de pagar a las cajas de comunidad los réditos de sus "inversiones" en la Caja de Consolidación con el fin de remitir ese dinero a los ejércitos españoles que peleaban en la península. Guatemala, A1, leg. 221, exp. 5197, f. 6. AGCA.
} 


\section{CUADRO 3. GUADRO 3. PAGOS DEL SERVICIO DE LA DEUDA PÚBLICA EN CHIAPAS, 1807-1819 (PESOS)}

\begin{tabular}{lr}
\hline Año & Monto destinado al servicio de la deuda \\
\hline 1807 & 222 \\
1808 & 305 \\
1809 & 1864 \\
1810 & 853 \\
1811 & 3409 \\
1812 & 0 \\
1813 & 0 \\
1814 & s. d. \\
1815 & 9000 \\
1816 & 6000 \\
1817 & 10000 \\
1818 & 12262 \\
1819 & 6062 \\
\hline
\end{tabular}

Fuente: Guatemala, A3, leg. 2018, exp. 30934; leg. 1945, exp. 30205; leg. 1346, exp. 22540; leg. 700, exp. 13059; B1.13, leg. 16, exp. 477, AGCA.

corto plazo (Obara-Saeki y Viqueira, 2017, pp. 152-157). Así, en el quinquenio que va de 1815 a 1819, los ingresos de la tesorería de Chiapas comenzaron a repuntar, pasando de 41267 pesos en el primer año a 96418 en el último.93

Lo anterior permitió a la caja de Ciudad Real pagar de forma más o menos puntual a los acreedores y, también, ponerse al corriente con el pago de los réditos que se debían desde 1812, incluso antes ${ }^{94}$ Así, durante el quinquenio de 1815-1819, la tesorería de la intendencia erogó en promedio 8664 pesos anuales para el pago del servicio de la deuda. Además, algunos capitales depositados a corto plazo en el ramo del real empréstito empezaron a ser amortizados. Sin embargo, como notará el lector, esta cifra se encuentra por debajo de lo que la tesorería debía erogar para cubrir el monto anual del servicio de la deuda.

Los documentos de la Real Hacienda permiten observar que, a pesar de que el pago del servicio de la deuda había mejorado, una buena parte de los acreedores seguían sin recibir el pago de sus utilidades. Este impago selectivo se debió fundamentalmente a un factor: el incremento en los gastos militares de la tesorería de Ciudad Real. Entre 1815 y 1816, los gastos extraordinarios asignados a esta crecieron como consecuencia de que las autoridades de Guatemala ordenaron acantonar dos unidades militares en la provincia, una en Ixtacomitán y la otra en Tuxtla, con la finalidad de proteger el territorio chiapaneco de las gavillas de insurgentes que aún merodeaban las áreas colindantes de la intendencia de Veracruz.

\footnotetext{
${ }^{93}$ Guatemala, B1, leg. 16, exp. 477, Ciudad Real, 30 de noviembre de 1820, f. 1. AGCA. El elevado nivel de ingresos en este último año obedeció a dos causas: $a$ ) que los subdelegados al fin consiguieron cobrar los atrasos del tributo de indios que se habían generado desde 1816 y $b$ ) que ya se estaba cobrando el tributo con base en el nuevo padrón de tributarios.

${ }^{94}$ Entre 1817 y 1818 -sobre todo durante este último año- se pagaron réditos vencidos desde 1807. Guatemala, A3, leg. 1346, exp. 22540. AGCA.
} 
Debido a esta situación, señalaron los ministros, "las existencias de las arcas apenas alcanzan para cubrir la suma que debe constituir el fondo militar de esta provincia" ${ }^{95}$ De este modo, parte del superávit de la caja de Ciudad Real se utilizó para pagar los intereses de algunas de las deudas contraídas con el clero, cuyas corporaciones presionaban constantemente para que sus pagos no fueran suspendidos. Los indios, por el contrario, no corrieron con la misma suerte. En 1821, año en que Chiapas declaró su independencia de España, los informes de la Hacienda pública mostraban que la corona jamás había pagado los réditos generados por la deuda que mantenía con las cajas de comunidad 96

\section{Conclusiones}

Entre 1780 y 1813 los principales instrumentos extraordinarios para el financiamiento del déficit imperial fueron los donativos y los préstamos a interés. Al igual que ocurrió en Nueva España, en Chiapas los donativos recaudados durante estos años tuvieron diversas modalidades. La mayor parte de estos fueron universales $(1781,1793,1798,1808$ y 1812) otros tuvieron el carácter de particulares, pues sólo se recaudaron entre sectores específicos de la población. Ejemplo de esto último es el donativo de 100000 pesos de 1809 que sólo se cobró a los pueblos de indios con el dinero de sus cajas de comunidad.

El instrumento más eficaz para financiar el esfuerzo bélico de la corona fue la deuda pública, es decir, la recolección de diversos préstamos a interés que en el caso de Chiapas afectaron únicamente a los pueblos de indios y a la Iglesia. Como mostramos, la primera medida de este tipo se registró en 1782, cuando las autoridades de Guatemala ordenaron al obispo de Chiapas depositar en las arcas de la Real Hacienda poco más de 14000 pesos cuyos réditos fueron pagados por la Factoría del Tabaco de Ciudad Real. Durante el gobierno de Carlos IV la recaudación de préstamo a interés aumentó. En 1799 la audiencia ordenó suscribir al préstamo las tres cuartas partes de los sobrantes de las cajas de comunidad de Chiapas, los cuales se invirtieron dos años después en la defensa de la costa atlántica del reino.

Con todo, la medida de endeudamiento más importante aplicada por la corona fue la Consolidación de los Vales Reales, la cual estuvo en vigor en Chiapas entre 1805 y 1808. Por medio de esta medida se enajenaron 179229 pesos. Sin embargo, todo indica que los efectos de la consolidación sobre la riqueza de la Iglesia chiapaneca fueron limitados. Así, la junta subalterna de Ciudad Real no consiguió que la mayor parte de los individuos que tenían en su poder capitales del clero en calidad de préstamo redimieran sus deudas, de tal forma que solamente recuperó 80000 de los poco más de 380000 pesos que las diversas corporaciones eclesiásticas de provincia tenían invertidos en censos perpetuos y a depósito irregular. Además, la consolidación fracasó al poner en venta las propiedades del clero chipaneco.

En este sentido, sólo $46 \%$ del total de fondos enajenados fue tomado de las arcas del clero, mientras que el resto provino de las cajas de comunidad de los pueblos de indios. Por ello, podemos afirmar que lo ocurrido en Chiapas durante la Consolidación de Vales Reales fue más bien una especie de amortización civil que absorbió el superávit de los erarios de los pueblos de indios.

${ }^{95}$ Chiapas, A3, leg. 336, exp. 4372, Ciudad Real, 8 de febrero de 1820, f. 12v. AGCA.

${ }^{96}$ Fondo Diocesano, carp. 4366, exp. 2. AHDSC. 
La demanda de préstamos creció durante los años de la crisis dinástica de la monarquía. Si bien la emisión de nueva deuda pública a través del ramo del real empréstito respondió en un primer momento a la necesidad de remitir fondos para las tropas que luchaban contra el ejército francés en la península, a partir de 1812 el dinero recolectado a través de este instrumento se canalizó a la manutención de las tropas que fueron movidas a Chiapas para repeler una eventual invasión de la insurgencia novohispana que había tomado la provincia de Oaxaca. Así, fueron de nueva cuenta los indios, por medio del dinero de sus cajas de comunidad, y la Iglesia quienes financiaron los nuevos empréstitos.

Entre 1804 y 1811, la tesorería de Chiapas comenzó a amortizar los préstamos de 1782 y 1801 y a cubrir parte de los réditos de la consolidación. Sin embargo, la crisis financiera del erario provincial entre 1812 y 1814 obligó a las autoridades a suspender completamente los pagos a los acreedores. Tras el restablecimiento del tributo, la salud del erario chiapaneco mejoró, de tal forma que se reactivó el pago de réditos y se pudo cubrir una parte de los adeudos atrasados. Sin embargo, como mostramos, durante el quinquenio de 1815-1819 la tesorería de Chiapas, a pesar de disponer de más recursos, incurrió en un impago selectivo. Si bien las utilidades del clero fueron cubiertas, los réditos de las cajas de comunidad no se pagaron a consecuencia de que ese dinero se canalizó a los gastos militares de la caja provincial. La consumación de la independencia en 1821 terminaría por sumir en el olvido las deudas contraídas por la corona con los pueblos de indios.

\section{LISTA DE REFERENCIAS}

Aguirre, R. (2014). El subsidio eclesiástico y la política de Felipe V en la Iglesia indiana: un camino por explorar. Tzintzun. Revista de estudios históricos, 60, 45-73.

Artola, M. (1982). La hacienda del Antiguo Régimen. Madrid: Alianza/Banco de España.

Cabat, G. A. (1971). The Consolidation of 1804 in Guatemala. The Americas, 28(1), 20-38. DOI: $10.2307 / 980342$

Carvalho, A. M. (1994). La ilustración del despotismo en Chiapas, 1774-1821. México: Consejo Nacional para la Cultura y las Artes.

Cobá, L. (2009). El “indio ciudadano”: la tributación y la contribución personal directa en Yucatán, 17861825. México: Instituto de Investigaciones Dr. José María Luis Mora/Universidad Autónoma de Yucatán.

Escamilla, F. I. (2011). Los intereses malentendidos. El Consulado de Comerciantes de México y la monarquía española, 1700-1739. México: Universidad Nacional Autónoma de México.

Fernández, B. (1993). El Reino de Guatemala durante el gobierno de Antonio González Saravia, 18011811. Guatemala: Comisión Interuniversitaria Guatemalteca de Conmemoración del Quinto Centenario del Descubrimiento de América.

Fernández, M. (2000). Los tributos en el reino de Guatemala, 1786-1821. Guatemala: Serviprensa.

Fortea, J. I. (2000). Los donativos en la política fiscal de los Austrias (1625-1637): ¿servicio o beneficio? En L. A. Ribot, L. De Rosa y C. Belloso (eds.), Pensamiento y política económica en la época moderna (pp. 31-76). Madrid: Actas.

Gil, F. (2015). De la negociación a la coerción: la recaudación del donativo de 1635. Studia Historica: Historia Moderna, 37, 211-234. DOI: 10.14201/shhmo201537211234

González, J. (2015). La experiencia colonial y transición a la independencia en el occidente de Guatemala. Quetzaltenango: de pueblo indígena a ciudad multiétnica, 1520-1825. Mérida: Universidad Nacional Autónoma de México/Centro Peninsular en Humanidades y Ciencias Sociales. 
Grafenstein, J. von. (2012). Situado y gasto fiscal: la Real Caja de México y las remesas para gastos militares en el Caribe, 1756-1783. En A. A. Carrara y E. Sánchez (eds.), Guerra y fiscalidad en la Iberoamérica colonial (siglos XVII-XIX) (pp. 155-142). Juiz de Fora/México: Universidade Federal de Juiz de Fora/Instituto de Investigaciones Dr. José María Luis Mora.

Guerra, F. X. (1992). Modernidad e independencias: ensayos sobre las revoluciones hispánicas. México: Fondo de Cultura Económica.

Gutiérrez, S. N. (2008). Vínculos sociales y políticos en el partido de Tuxtla, provincia de Chiapas, en el último cuarto del siglo xviII. Diálogos Revista Electrónica, 9, 656-666. DOI: 10.15517/v. v9i0.31189

Hawkins, T. (2013). El mito del terror bustamantino. En A. Pollack (ed.), La época de las independencias en Centroamérica y Chiapas. Procesos políticos y sociales (pp. 159-188). México: Instituto de Investigaciones Dr. José María Luis Mora/Universidad Autónoma Metropolitana.

Klein, H. S. (1994). Las finanzas americanas del imperio español, 1680-1809. México: Instituto de Investigaciones José María Luis Mora.

Lanza, R. (2010). El donativo de 1629 en la Andalucía bética. Studia histórica. Historia moderna, $32,179-227$.

Laughlin, R. M. (2001). La gran serpiente cornuda. iIndios de Chiapas, no escuchen a Napoleón! México: Universidad Nacional Autónoma de México, Instituto de Investigaciones Dr. José María Luis Mora.

Marichal, C. (1995). La Iglesia y la corona: la bancarrota del gobierno de Carlos IV y la consolidación de vales reales en Nueva España. En M. del P. Martínez (ed.), Iglesia, estado y economía, siglos XVI al XIX (pp. 241-261). México: Universidad Nacional Autónoma de México/Instituto de Investigaciones Dr. José María Luis Mora.

Marichal, C. (1999). La bancarrota del virreinato. Nueva España y las finanzas del imperio español, 1780-1810. México: El Colegio de México/Fondo de Cultura Económica.

Nardi, L. (2018). Los donativos voluntarios: un aspecto poco estudiado de la política americana de los Habsburgo de España (Siglos XVI-XviII). América Latina en la Historia Económica, 25(1), 7-35. DOI: $10.18232 /$ alhe.857

Obara-Saeki, T. y Viqueira, J. P. (2017). El arte de contar tributarios. Provincia de Chiapas, 15601821. México: El Colegio de México.

Parrilla, A. M. (2017). Subdelegados y ayuntamientos en la intendencia de Ciudad Real: negociación e imposición. VII Congreso de la Red de Estudios del Régimen de Subdelegaciones en la América Borbónica. Presentado en Tuxtla Gutiérrez, Chiapas, México. Tuxtla Gutiérrez, Chiapas, México: Universidad de Ciencias y Artes de Chiapas/El Colegio de Michoacán.

Payne, E. (2013). Poderes locales y resistencia popular en Nicaragua 1808-1813. En A. Pollack (ed.), La época de las independencias en Centroamérica y Chiapas. Procesos políticos y sociales (pp. 123158). México: Instituto de Investigaciones Dr. José María Luis Mora/Universidad Autónoma Metropolitana.

Pollack, A. (2008). Levantamiento k’iche’ en Totonicapán, 1820. Los lugares de las políticas subalternas. Guatemala: Asociación para el Avance de las Ciencias Sociales en Guatemala.

Pollack, A. (2016). Hacia una historia social del tributo de indios y castas en Hispanoamérica. Notas en torno a su creación, desarrollo y abolición. Historia mexicana, 66(1), 65-160.

Quezada, S. y Moreno, E. (2005). Del déficit a la insolvencia. Finanzas y real hacienda en Yucatán, 1760-1816. Estudios Mexicanos, 21(2), 307-331. DOI: 10.1525/msem.2005.21.2.307 
Quiroz, A. W. (1993). Deudas olvidadas. Instrumentos de crédito en la economía colonial peruana 17501820. Perú: Pontificia Universidad Católica del Perú.

Ruz, M. H. (1992). Savia india, floración ladina: apuntes para una historia de las fincas comitecas (siglos xviii y xix). México: Consejo Nacional para la Cultura y las Artes.

Sánchez, E. (2012). Los impactos fiscales de una guerra distante: crisis y restauración de la Real Hacienda en la provincia de Yucatán (1801-1821). Revista de Historia Económica, 30(3), 323352. DOI: $10.1017 / \mathrm{S} 0212610912000158$

Sánchez, E. (2015). Constitucionalizar el orden fiscal en Nueva España: de la Ordenanza de Intendentes a la Constitución de Cádiz (1786-1814). Historia mexicana, 65(1), 111-165.

Sánchez, E. (2016a). Deudas y préstamos: la crisis del crédito público en Nueva España durante la guerra de independencia (1810-1821). América Latina en la Historia Económica, 23(2), 36-63. DOI: $10.18232 /$ alhe.v23i2.708

Sánchez, E. (2016b). La imperiosa necesidad. Crisis y colapso del erario de Nueva España (1808-1821). México: Instituto de Investigaciones Dr. José María Luis Mora/El Colegio de Michoacán.

Serrano, J. A. (2007). Igualdad, uniformidad, proporcionalidad. Contribuciones directas y reformas fiscales en México, 1810-1846. México: Instituto de Investigaciones Dr. José María Luis Mora/El Colegio de Michoacán.

Tanck, D. (1994). Escuelas y cajas de comunidad en Yucatán al final de la colonia. Historia Mexicana, 43(3), 401-449.

Torres, R. (2008). Las prioridades de un monarca ilustrado o las limitaciones del Estado fiscalmilitar de Carlos III. Hispania, 68(229), 407-436. DOI: 10.3989/hispania.2008.v68.i229.84

Torres, R. (2013). El precio de la guerra: el estado fiscal-militar de Carlos III (1779-1783). Madrid: Marcial Pons.

Truchuelo, S. (2008). Privilegios y libertades fiscales: los donativos al monarca en los territorios vascos y Cataluña en el período altomoderno. Pedralbes: Revista d'historia moderna, 28(1), 283300.

Valle, G. del. (2012). Finanzas piadosas y redes de negocios: los mercaderes de la Ciudad de México ante la crisis de Nueva España, 1804-1808. México: Instituto de Investigaciones Dr. José María Luis Mora.

Valle, G. del. (2016). Donativos, préstamos y privilegios: los mercaderes y mineros de la Ciudad de México durante la guerra anglo-española de 1779-1783. México: Instituto de Investigaciones Dr. José María Luis Mora.

Wobeser, G. von. (2003). Dominación colonial. La consolidación de vales reales en Nueva España, 18041812. México: Universidad Nacional Autónoma de México.

Wortman, M. L. (2012). Gobierno y sociedad en Centroamerica, 1680-1840. Guatemala: Universidad Rafael Landívar.

Archivos

agca Archivo General de Centroamérica, Guatemala, Guatemala.

AGI Archivo General de Indias, Sevilla, España.

AHEc Archivo Histórico del Estado de Chiapas, Tuxtla Gutiérrez, Chiapas, México.

AHDSc Archivo Histórico Diocesano de San Cristóbal de Las Casas, Chiapas, México.

AHN Archivo Histórico Nacional, Madrid, España. 